\title{
José Joaquín Fernández de Lizardi oder der euro- päische Schelmenroman in Amerika
}

In ihrer bereits angeführten Literaturgeschichte des spanischsprachigen Amerika seit der Independencia hat Jean Franco die Literatur Hispanoamerikas in den Kontext unterentwickelter Länder gestellt, die der Dritten Welt angehören. ${ }^{1}$ Das ist in der Sache - gelinde gesagt - ebenso aussageschwach wie irreführend. Für eine adäquate Analyse und Erkenntnis der Grundbedingungen des Schreibens im 19. Jahrhundert ist es gänzlich ineffektiv und anachronistisch, sind Unterentwicklung und Dritte Welt doch Begriffe, die erst in der zweiten Hälfte des 20. Jahrhunderts aufkamen, nach dem Zweiten Weltkrieg also. Im 19. Jahrhundert befinden wir uns lange vor jener Zeit, in der die Lateinamerikaner aus Sicht des sogenannten,Westens ' und insbesondere der USA pauschal zu Unterentwickelten gerechnet und ihre jungen Nationen in die ebenso bequeme wie problematische Kategorie „Dritte Welt“ eingeordnet werden konnten. Wir sollten folglich versuchen, eine unserem Gegenstand angemessenere und analytischere Begrifflichkeit zu finden.

Gemäß der in den sechziger und siebziger Jahren zumindest im kritisch links einzuordnenden Spektrum vorherrschenden Dependenztheorie wurde auch sehr häufig von einer „kulturellen Dependenz“ Lateinamerikas und der lateinamerikanischen Kulturen gesprochen, wobei man diesmal einfach die Begriffe nicht aus der politischen, sondern aus der wirtschaftswissenschaftlichen Sphäre auf den Bereich von Kunst, Kultur und Literatur übertrug. Es wird Sie nicht überraschen, dass ich den Begriff der Asymmetrie zur Untersuchung transatlantischer Kulturbeziehungen für zutreffender halte.

Dass es eine Abhängigkeit Lateinamerikas von Europa und später den USA gab und gibt, welche sich auch im kulturellen Sektor auswirkte und bemerkbar machte, ist naturgemäß unbestritten und unbestreitbar. Aber mit Hilfe derartiger Begrifflichkeiten wird doch allzu sehr die Passivität betont, erscheint lateinamerikanische Kultur daher zumeist als (eher recht glanzloser und unorigineller) Reflex des literarischen Lebens in Europa, so dass mit Blick auf das 18. oder 19. Jahrhundert allzu leicht die bereits erwähnten aktiven Prozesse kultureller Transformation und Subversion übersehen werden. Asymmetrie ist dagegen keine kulturelle oder literarische Einbahnstraße, sondern lässt den Dialog und Polylog, den fruchtbaren Austausch zu, ohne doch zu übersehen, dass diese internationalen Kulturbeziehungen in einem fundamentalen Relationsgeflecht struktureller Ungleichheit angesiedelt sind.

1 Franco, Jean: Historia, S. $11 \mathrm{f}$.

2 Open Access. (c) 2021 Ottmar Ette, publiziert von De Gruyter. (c))BY-NC-ND Dieses Werk ist lizensiert unter einer Creative Commons Namensnennung - Nicht-kommerziell - Keine Bearbeitung 4.0 International Lizenz. https://doi.org/10.1515/9783110703443-013 
Lassen Sie uns nun aber zur Interpretation eines ersten literarischen Textes übergehen, der zudem gemeinhin als der erste wirkliche lateinamerikanische Roman gilt - oder genauer: als der erste von einem Hispanoamerikaner in Hispanoamerika verfasste! Wir werden dabei schnell bemerken, wie kurz die Kategorie der kulturellen Dependenz greift und wie sehr sie den Blick verengt, so dass die kreative literarische Dimension in den interkulturellen und intertextuellen Beziehungen deutlich zu wenig gewichtet wird. Es handelt sich um den 1816 veröffentlichten Text El Periquillo Sarniento. Sein Verfasser ist der in Europa weitgehend unbekannte neuspanische beziehungsweise mexikanische Schriftsteller, Essayist und Publizist José Joaquín Fernández de Lizardi.

Der neuspanische Autor wurde am 15. November 1776 in Mexiko-Stadt geboren und starb daselbst am 21. Juni 1827. Wir können bei ihm eine Entwicklung beobachten, die wir in etwa zeitgleich in der Kunst bei Francisco de Goya sehen: die Entwicklung hin zu einem Berufsschriftsteller, zu einem Autor, der als Publizist, Romancier und Journalist von seiner literarischen Feder erstmals leben konnte eine fürwahr wichtige Tatsache! Wir werden uns diese Entwicklung genauer mit Hilfe jenes Textes ansehen, der ihn berühmt machte und den wir ausführlich entlanggehen wollen, um seine verschiedenen Ebenen in einem Close Reading zu untersuchen und zu interpretieren.

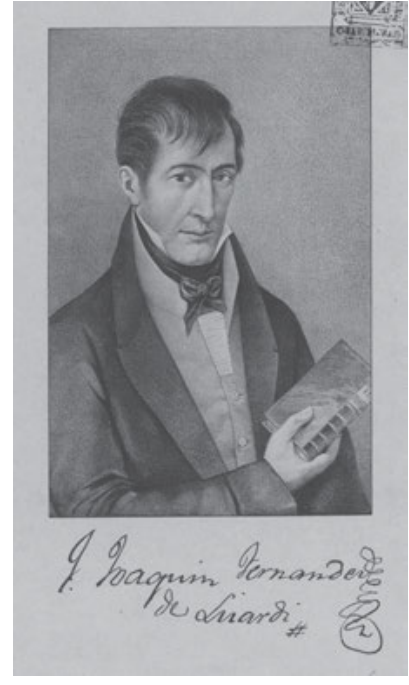

Abb. 29: José Joaquín Fernández de Lizardi (Mexiko-Stadt, 1776 - ebenda, 1827).

Ich ziehe ein solches Verfahren gegenüber einer Trennung von Inhalt und Interpretation vor, möchte folglich den zu untersuchenden Text gemeinsam mit Ihnen erarbeiten. Es sollte sich inzwischen herumgesprochen haben, dass jede Inhaltsangabe auch schon eine Interpretation ist, freilich eine, die sich selten zu 
erkennen gibt und - schlimmer noch - dem Nach-Erzähler meistens nicht einmal selbst bewusst ist. Nicht immer werden wir uns für einen literarischen Text so viel Zeit nehmen können; doch scheint es mir in diesem Falle angebracht, handelt es sich doch bei El Periquillo Sarniento nicht um das Romandebüt eines bestimmten Autors, sondern der gesamten Welt des lateinischen Amerika.

Der Text setzt ein mit einer ganzen Serie von Vorworten, auf die ich zu einem späteren Zeitpunkt noch genauer zu sprechen kommen werde: „Prólogo, dedicatoria y advertencias a los lectores“, gefolgt von „El Prólogo de Periquillo Sarniento“ und schließlich die „Advertencias generales a los lectores“. Dies sind Paratexte, die es in sich haben, in einigen Ausgaben aber leider - wie dies so oft mit Vorworten und anderen Paratexten geschieht - schlicht übersehen und ausgelassen wurden. Festgehalten sei an dieser Stelle nur, dass wir es mit einer Herausgeberfiktion zu tun haben, mit anderen Worten also, dass es eine Textinstanz gibt, die sich explizit auf die Rolle beschränkt, den Text, den ein anderer verfasst habe, $z u$ publizieren und höchstens zu kommentieren. Dies ist die Rolle jener Instanz, die sich explizit als Fernández de Lizardi beziehungsweise „El Pensador“ bezeichnet; und wir sollten uns hüten, diese Instanz mit dem realen Autor - der stets eine textexterne Instanz ist - zu verwechseln: Der Herausgeber ist also nicht der reale Autor José Joaquín Fernández de Lizardi, sondern eine Herausgeberfiktion, auf die ich gleich nochmals zurückkomme.

Das Verfahren ist aus der Gattungsgeschichte des abendländischen Romans wohlbekannt. Es bietet dem realen Autor einen gewissen Schutz, kann dieser sich doch gegenüber seinem Text, den er nur herauszugeben vorgibt, eine gewisse Distanz verschaffen - ein literarisches Verfahren, wie es in einem der wohl bekanntesten Romane des 18. Jahrhunderts, Julie ou La Nouvelle Héloïse, von JeanJacques Rousseau erfolgreich praktiziert wurde. Mit Hilfe dieses sowie anderer Verfahren eroberte sich der Genfer Philosoph und Literat den notwendigen Freiraum, eine Fülle gesellschaftskritischer beziehungsweise philosophischer Reflexionen in den Text einzuschleusen, ohne dafür als Autor direkt verantwortlich zeichnen zu müssen. Das Verfahren hat den Vorteil, nicht auf die direkte Kommunikation mit dem angezielten Lesepublikum - und damit auf eine Direktheit der Kritik - verzichten zu müssen. Denn diese Kritikpunkte und Reflexionen in Rousseaus Briefroman konnten doch jeweils einer bestimmten Romanfigur in den Mund - oder besser: in die Feder - gelegt werden, wobei sich der reale Autor damit verteidigen konnte, lediglich die Briefe seiner Romanfiguren auf einem verlassenen Speicher aufgefunden und herausgegeben zu haben.

Rousseau hat die Herausgeberfiktion beileibe nicht erfunden: Die Geschichte dieses Verfahrens ist so lange wie die des modernen abendländischen Romans, findet es sich doch bereits in Miguel de Cervantes’ Don Quijote de la Mancha, dem nach den pikaresken Anfängen gewiss ersten modernen Roman der europäischen 
Geschichte der Gattung. Da dieser Roman auch für Fernández de Lizardi von einiger Bedeutung war und im Periquillo Sarniento des Öfteren liebevoll gestreift wurde, möchte ich Ihnen gerne Cervantes' berühmte Passage der Herausgeberfiktion in Erinnerung rufen:

Als ich „Dulcinea del Toboso“ sagen hörte, hielt ich stille und verstummte, weil mir nunmehr vor Augen stand, jene Päckchen könnten die Geschichte von Don Quijote enthalten. Mit dieser Vorstellung im Kopf drängte ich ihn, rasch den Anfang zu lesen, und als dem so geschah und er unverrücks vom Arabischen ins Kastilische hinüberwechselte, sagte er, es heiße: „Geschichte des Don Quijote de la Mancha, verfasst von Cide Hamete Benengeli, dem arabischen Geschichtsschreiber.“ Viel Diskretion war vonnöten, um mir meine Zufriedenheit nicht anmerken zu lassen, die ich empfand, als mir der Titel des Werkes in den Ohren erklang [...]. ${ }^{2}$

Wie Sie sehen, wird in dieser Passage recht kunstvoll in den Ablauf der Handlung gleich zu Beginn des Romans (im berühmten neunten Kapitel) die Fiktion eines anderen Autors eingeführt - eben jenes arabischen Geschichtsschreibers namens Cide Hamete Benengeli. Der Verfasser verschanzt sich hinter einer von ihm erfundenen Fiktion als reiner Herausgeber eines Werkes, das ein anderer geschrieben habe. Der reale Autor Fernández de Lizardi tut dies in seinem Vorwort, nimmt dann aber diese Ebene nochmals am Ende der von ihm entworfenen Geschichte auf, indem er die Herausgeberfigur Fernández de Lizardi ausführlich bespricht und $\mathrm{zu}$ einem Freund seines Protagonisten Periquillo Sarniento werden lässt. Dieser, so erfahren wir dann, habe dereinst das Buch zur Belehrung seiner Kinder verfasst und ihm anvertraut. Nach Klärung der Rechte - so könnten wir das heute nennen -, also nach Einholen des Einverständnisses der Witwe des Verstorbenen, habe dieser Lizardi dann die Geschichte Periquillo Sarnientos zur Belehrung einer breiteren Öffentlichkeit ans Tageslicht (beziehungsweise unter die Druckerpresse) gebracht. Indem sich Fernández de Lizardi auf dieses fundamentale Verfahren des Quijote bezog, schrieb er sich in den Augen seiner Zeitgenossen unverkennbar ein in die lange Geschichte des europäischen Romans - mit allen Konsequenzen, die wir im Folgenden erörtern werden. Doch zuvor wollen wir versuchen, uns diesem umfangreichen Text von seiner ihm heute zugeschriebenen literarhistorischen Bedeutung her zu nähern.

In seinem vielbeachteten Essay über die Herausbildung des lateinamerikanischen Romans hat der uruguayische Kritiker und Literaturtheoretiker Angel

2 Cervantes Saavedra, Miguel de: El ingenioso hidalgo Don Quijote de la Mancha. Primera parte. Leipzig: Brockhaus 1866, Capitulo IX, S. 39. 
Rama die These vertreten, José Joaquín Fernández de Lizardis Roman El Periquillo Sarniento sei von einer ihm zugrunde liegenden ,archaischen“ Struktur geprägt:

Der Schelm oder Pícaro, den Lizardi erfindet, ist nicht nur ein thematischer, sondern auch formaler Archaismus. Er restauriert die ursprüngliche Bedingung des Romans als Waffe im Kampf um die Zerstörung einer etablierten Ordnung, wobei er sich der klassischen List (der einzigen List, welche diese Ordnung im Übrigen zuließ) des verantwortungslosen Sprechens des gesellschaftlich Marginalisierten, des Enterbten oder Verrückten, des Lazarus oder Quijote bediente. ${ }^{3}$

Damit scheinen in den Augen Ramas jene Koordinaten festgeschrieben, die dem Roman in Lateinamerika einen eher zweitrangigen Status zuweisen, seien doch Lyrik und Essay - folgten wir seiner Argumentation - nicht nur die bevorzugten, sondern zugleich auch die ,durchdringenderen` Gattungsformen, die sich während der beiden zurückliegenden Jahrhunderte im spanischsprachigen Amerika ausgebildet hätten. Angesichts der von Rama im Übrigen häufig behandelten Erfolgsstory der Autoren und Romane des sogenannten ,Boom' enthält diese These mehr Verwirrendes als Aufhellendes, auch wenn sie mit literarsoziologischem Befund untermauert wird:

Von diesem Auftakt an wird der lateinamerikanische Roman nichts anderes tun als eine bekannte Geschichte zu wiederholen: die nämlich eines Hin und Her der engen Verbindung zwischen einer Gattung und einer gesellschaftlichen Klasse, die zu Beginn des 19. Jahrhunderts jene der Kaufmanns- und Funktionsbourgeoisie ist. Durch eine Abfolge fast zufälliger Ereignisse gesellt sich dem die Führung der neuen unabhängigen Staaten und die Unterwerfung riesiger heterogener Bevölkerungen unter deren Normen bei, welche im Zaum zu halten es mehr als ein halbes Jahrhundert braucht. ${ }^{4}$

Die enge Verbindung zwischen dem aus Europa bekannten Aufstieg des Bürgertums und des gleichzeitigen Aufstiegs der Gattung Roman wird auf dem amerikanischen Kontinent durch die Unabhängigkeitsrevolution und die Errichtung einer neuen gesellschaftlichen Elite nicht grundlegend in Frage gestellt, sondern lediglich modifiziert und insgesamt bestätigt. Doch der Vorwurf des Archaismus und der Unzeitgemäßheit lastet - dies verdeutlicht die Argumentation des uruguayischen Literarhistorikers - schwer auf Fernández de Lizardis 1816 in unvollständiger Form erstmals veröffentlichtem Debüt-Roman.

3 Rama, Angel: La formación de la novela latinoamericana. In (ders.): La novela en América Latina. Panoramas 1920-1980. Montevideo - Xalapa: Fundación Angel Rama - Universidad Veracruzana 1986, S. 21.

4 Ebda. 
Denn die Verknüpfung zwischen der Herausbildung des Romans und der soziopolitischen Entwicklung der unabhängig gewordenen lateinamerikanischen Nationen, die hier geradezu selbstverständlich erfolgt, wird von Rama in der narrativen Modellierung einer Urschuld präsentiert. Es handelt sich dabei um die schuldhafte Verstrickung des lateinamerikanischen Romans mit den Zielen und Absichten einer einzigen gesellschaftlichen Klasse, die als Sprachrohr für ihre Forderungen allein die Figur des spanischen „Pícaro“, des Enterbten oder Verrückten, akzeptiert habe. Roman und Nation scheinen in Lateinamerika ab initio vom selben Virus befallen: vom Virus ihrer Funktionalisierung durch Normen und Werte des aufstrebenden Bürgertums, Normen freilich, welche erst nach einem halben Jahrhundert unterschiedlichster Formen des Bürgerkriegs und des Kampfes auf amerikanischem Boden durchgesetzt werden konnten. Aber war $E l$ Periquillo Sarniento wirklich - wie von Rama behauptet - ,archaisch“ und unzeitgemäß, hinkte er seiner Zeit der Unabhängigkeitsrevolution hinterher?

In der Tat ist es verlockend, vor dem Hintergrund einer nachweisbaren relativen Gleichzeitigkeit die literarische mit der politischen Formgebung auf dem amerikanischen Kontinent in Verbindung zu bringen, ja Romanschöpfung und Nationenbildung miteinander zu parallelisieren. Dies kann, wie etwa bei Rama, in negativ eingefärbter Weise erfolgen, aber auch deutlich positive Vorzeichen erhalten wie bei Noël Salomon, der Fernández de Lizardis Roman in einem vielzitierten Aufsatz schlicht als „la novela de la independencia mexicana“, ${ }^{5}$ als den Roman der mexikanischen Unabhängigkeit bezeichnete. Zwei Kritiker, zwei Meinungen: In beiden Fällen wäre die relative Gleichzeitigkeit der Ereignisse nicht kontingent, sondern epistemologisch wirksam im selben generierenden Kontext zu verorten. Aber wer hatte nun Recht?

Führen wir diesen Gedanken weiter, so könnten wir den von Rama behaupteten Archaismus auf thematischer wie formaler Ebene als Paradoxon (und zugleich als Aporie) deuten und für die Entwicklungsgeschichte des Romans in Lateinamerika doch noch fruchtbar machen. Denn was wäre zeitgemäßer und aktueller innerhalb einer anachronistisch im kolonialspanischen System verwurzelten neuspanischen Gesellschaft als eben jene von Spanien ererbte Figur des „Pícaro“? Der als anachronistisch gebrandmarkte Schelmenroman - der im Übrigen bis in unsere Tage weder in Amerika noch in Europa viel von seiner kritischen Wirkkraft und ästhetischen Potenz verloren hat - erwiese sich so als eben jene Form, welche die literarästhetisch überzeugendste Antwort auf die spezifische Situation Neuspaniens am Ausgang seiner langen Kolonialgeschichte zu geben vermag.

5 Salomon, Noël: La crítica del sistema colonial de la Nueva España en „El Periquillo Sarniento“. In: Cuadernos Americanos (México) XXI, 138 (1965), S. 179. 
In der Tat soll El Periquillo Sarniento - soweit dürfen wir den nachfolgenden Ausführungen aus didaktischen Gründen etwas vorgreifen - als innerhalb neuer gesellschaftlicher, politischer und historischer Kontexte resemantisierte und refunktionalisierte literarische Form verstanden werden, durch welche Alte und Neue Welt in einen schöpferischen Polylog, mittelfristig sogar in eine kreative Wechselbeziehung miteinander verwickelt werden. Aus einer solchen Perspektive betrachtet wäre dann die Beziehung zwischen Roman und Nation weder eine zu geißelnde Verstrickung noch eine zu begrüßende zukunftsträchtige Befreiung. Sie erwiese sich als ein dynamisches und dynamisierendes Element, das zweifellos gattungskonstitutiv verstanden werden könnte, ohne doch die gänzlich anders modellierten Räume von literarischer Äußerung und nationaler Genese als analog strukturierte Aspekte ein und desselben geschichtlichen Prozesses zu verstehen und unvermittelt aufeinander zu beziehen.

Wir haben damit in Anschluss an Angel Rama eine Fragestellung erreicht, die nach der Verbindung zwischen Gattungs- und Gesellschaftssystem fragt und damit eine grundlegende Problematik literatursoziologischer Forschungen betrifft, welcher einst Erich Köhler den programmatischen ersten Aufsatz seiner neuen literatursoziologisch ausgerichteten Zeitschrift widmete. ${ }^{6}$ Diese Fragestellung versetzte uns in die Lage, die Offenheit der Lizardi'schen Romankonstruktion für die Zukunft zurückzugewinnen und von Fernández de Lizardi verwendete narrative Gattungsspezifika der „Novela picaresca“ wie auch der Utopie als Beziehungsgeflechte eines polylogischen Schreibens zu verstehen, das weder als archaisch noch als anachronistisch fehlgedeutet werden sollte. Denn Angel Ramas Einschätzungen können wir getrost hinter uns lassen!

Wir sollten unsere Lektüre mit Hilfe dieser Überlegungen zugleich von einem zweiten, die Rezeptionsgeschichte von Fernández de Lizardis El Periquillo Sarniento bis heute belastenden Vorwurf befreien, demzufolge diesem Text eine monologische und dogmatische Grundstruktur anhafte. Den vielleicht drastischsten Beleg für diese noch immer anhaltende Kritik liefert uns der Mexikaner Carlos González Peña. Er zögerte 1910 nicht, im intellektuellen Kontext des Ateneo - und vor dem Hintergrund einer weiteren sich anbahnenden Revolution in Mexiko Fernández de Lizardis Roman als ,el más abominable sermón de que las letras nacionales tienen memoria“ zu bezeichnen, ${ }^{7}$ also als die ,grässlichste Predigt, von der unsere nationale Literaturgeschichtsschreibung Kenntnis habe“.

6 Vgl. hierzu Köhler, Erich: Gattungssystem und Gesellschaftssystem. In: Romanistische Zeitschrift für Literaturgeschichte (Heidelberg) 1 (1977), S. 7-22.

7 González Peña, Carlos: El Pensador Mexicano y su tiempo. In: Conferencias del Ateneo de la Juventud. México, D.F.: Imprenta Lacaud 1910, p. 102; zitiert nach Skirius, John: Fernández de Lizardi y Cervantes. In: Nueva Revista de Filología Hispánica (México) XXXI, 2 (1982), p. 259. 
Aber warum kam der mexikanische Kritiker zu einer solchen Einschätzung? Zweifellos sind es die zahlreichen diskursiven Einschübe und Digressionen und nicht so sehr (wie noch Rama meinte) die Figur des Pícaro selbst, die bis in unsere Gegenwart verschiedensten Formen adäquater Rezeption im Wege stehen. Auch wenn in El Periquillo Sarniento Predigten vorkommen: Um Predigten ging es hierbei wohl kaum, sondern insgesamt um die in den Roman integrierten Diskurse. Aber behinderten sie wirklich dessen adäquate Rezeption?

Wir sollten uns davor hüten, ein ,Moralisieren' mit Monologisieren und die komplexe Struktur dieses Romans mit jener einer Predigt gleichzusetzen. Die nachfolgende Analyse soll zeigen, in welch subtiler und komplexer Weise dialogische Strukturen in Fernández de Lizardis Schreiben eingewoben sind und wie sehr es uns die Bewusstmachung dieser Strukturierungen erlaubt, jenseits dieser beiden auf diesem „texto fundador“ lastenden Vorwürfe die historische Tiefenschärfe wie auch die ästhetische Leistung von Fernández de Lizardis Romanerstling herauszuarbeiten. Damit ist nicht allein der Wert des Periquillo Sarniento als zeitgeschichtliches Dokument gemeint. Fraglos ist dieser Roman ein Fenster in der Zeit, eine „ventana abierta hacia el pasado“; ${ }^{8}$ doch dürfen wir darüber - ganz im Derrida'schen Sinne ${ }^{9}$ - nicht den kunstvoll verfertigten Rahmen vergessen, der den Raum dieses „ersten im eigentlichen Sinne spanisch-amerikanischen Romans“, dieser „primera novela propiamente hispanoamericana“10 in der Zeit konfiguriert.

Wenden wir uns nun aber - wie angekündigt - der komplexen Paratextualität $\mathrm{zu}$, die Lizardis neuspanischen Schelmenroman begleitet und uns enorm wichtige Hinweise für eine adäquate Lektüre liefert! Der Vorwurf predigtartigen Monologisierens und moralisierender Langatmigkeit hat in der Editionsgeschichte wohlmeinende Herausgeber auf den Plan gerufen und $\mathrm{zu}$ verschiedenen ,Lösungen“ angeregt, das Geschäft des Lesepublikums ,einfacher‘ zu gestalten. Beispielhaft hierfür - sieht man von der gängigen Praxis gekürzter Ausgaben einmal ab ist eine mexikanische Edition von 1942, die ihrem Leser den Schnelldurchgang durch den Periquillo Sarniento mit Hilfe einer Kursivsetzung all jener Passagen zu erleichtern versuchte, die man der Rubrik „Digression“ zuordnen konnte. ${ }^{11}$ Oder aber wir betrachten - radikaler und pragmatischer noch - jene englischspra-

8 Ebda., S. 258.

9 Derrida, Jacques: La vérité en peinture. Paris: Flammarion 1978.

10 Iñigo Madrigal, Luis: José Joaquín Fernández de Lizardi. In (ders., Hg.): Historia de la literatura hispanoamericana. Bd. II: Del neoclasicismo al modernismo. Madrid: Cátedra 1987, S. 143. 11 Vgl. Vogeley, Nancy: Defining the „Colonial Reader“: „El Periquillo Sarniento“. In: PMLA (New York) CII, 5 (1987), S. 798. 
chige Ausgabe, welche ebenfalls im selben Jahr 1942 erschienen ist und auf derlei ,Beiwerk' verzichten zu können glaubte und sich auf das vermeintlich Essentielle beschränkte. ${ }^{12}$ Angelsachsen waren schon immer Pioniere stark raffender Lesepragmatik.

Merken wir an dieser Stelle tröstlich an: Eine derartige Vorgehensweise hat innerhalb der Editions- und Übersetzungsgeschichte des europäischen Schelmenromans berühmte Vorbilder, strich doch kein Geringerer als Alain-René Lesage in seiner Neuübersetzung von Mateo Alemáns Guzmán de Alfarache kurzerhand all jene Passagen heraus, die er für überflüssiges Moralisieren („,moralités superflues“) hielt. ${ }^{13}$ Seien wir freilich vorsichtig: Denn was dabei als „Moral von der Geschicht”“ und als ein „Moralisieren“ verstanden werden kann, ist jeweils einem ganz bestimmten Zeitkontext geschuldet.

Nicht viel besser erging es den zahlreichen Paratexten, die Fernández de Lizardi seinem Roman in Form von Vorworten, Widmungen, Motti, Anmerkungen oder herausgeberischen Intermezzi an die Seite stellte, wurden doch auch sie in einer Vielzahl von Ausgaben offenkundig aus Platzgründen , ausgespart‘. Die Sensibilität gegenüber all jenen „Schwellentexten“, die einen literarischen Text im Sinne Gérard Genettes als „Schwellen“ begleiten, ${ }^{14}$ aber nicht den ,eigentlichen“ Text ausmachen, ist unverkennbar zeit- und kontextabhängig. Das Fortlassen dieser Elemente aber bewirkt einen völlig veränderten Zugang des Lesepublikums zum gesamten Roman und löscht die Spuren subtiler Arbeit am Text aus. Diese auf die paratextuelle Dimension gerichtete Arbeit des Schriftstellers am Text ist von größter Bedeutung nicht nur für das weite Untersuchungsfeld der von Fernández de Lizardi bewusst eingesetzten literarischen Verfahren, sondern auch für die hier analysierte Problematik des Zusammenhangs zwischen Roman und Nation im Spannungsfeld hispanoamerikanisch-europäischer Literaturbeziehungen, also jener „Literaturen zwischen zwei Welten“, die im Zentrum unserer Vorlesung stehen.

Die starke Proliferation paratextueller Elemente stellt ein Wesensmerkmal dieses ersten Romans Fernández de Lizardis dar. Dies betrifft insbesondere die Vorworte, die unserem Roman in vielfacher Weise beigegeben sind, als SchwellenTexte zu Beginn des Romans, die ich bereits aufgezählt habe. Darüber hinaus erheben im weiteren Fortgang des Romans ein „Prólogo en traje de cuento“ sowie die „Notas del Pensador“ erneut Anspruch auf die Aufmerksamkeit der Leser-

12 Vgl. Skirius, John: Fernández de Lizardi y Cervantes, S. 258.

13 Vgl. hierzu u.a. die schöne Einführung von Micó, José María: Introducción. In: Alemán, Mateo: Guzmán de Alfarache. Bd. 1. Madrid: Cátedra ${ }^{3} 1994$, S. 40.

14 Vgl. Genette, Gérard: Seuils. Paris: Seuil 1987. 
schaft. Diese wird gleich zu Beginn des ersten Vorworts direkt als „Señores míos“ briefformelhaft angesprochen; eine Referenz, die in der Gattungsgeschichte eine direkte Verbindung zum anonymen Lazarillo de Tormes herstellt, mit dem El Periquillo Sarniento im Übrigen auch das paratextuelle Element des Titeldiminutivs verbindet. Die paratextuelle Arbeit des neuspanischen Autors ist folglich alles andere als von lediglich marginaler Bedeutung.

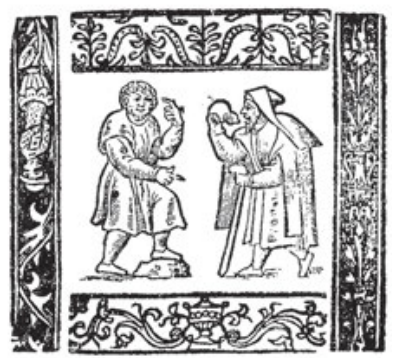

$$
\begin{aligned}
& \text { \& } \\
& \widetilde{z} 02 m e s / y \text { ose fus foztungs: } y \\
& \text { adueridadeg. thueuanente impecfe, } \\
& \text { cozregida, y oe nueuo añadi: } \\
& \text { da enefta fegúdaim" } \\
& \text { prefíion. }
\end{aligned}
$$

Abb. 30: Titelblatt einer der vier Erstausgaben von La vida de Lázaro de Tormes, 1554.

Verweisen gleich die ersten paratextuellen Markierungen mithin auf die spanische Gattungstradition, die gleichsam in autobiographischer Variation durch die Verwendung eines Zitats von Torres Villarroel als Motto des gesamten Textes die Kontinuität autobiographischer Schreibformen paratextuell in unseren Roman einblendet, so ist die Wendung an die Leser doch gänzlich verschieden von Lazarillos Anrede „Vuestra Merced“. Bei letzterer handelt es sich um jene rätselhafte Figur, der schon immer das Interesse und die Neugier der Lazarillo-Forschung galt. ${ }^{15}$ Denn dieses Modell eines Schreibens im Auftrag einer höhergestellten Persönlichkeit wird schon in (und zwischen) den ersten Zeilen dieses Vorworts transgrediert: Nicht umsonst verknüpft dieser kurze Text die Funktionen von „prólogo“, „dedicatoria“ und „advertencias“ miteinander:

15 Beispielhaft für die in der Forschung gerne gestellte Frage ist die Studie von Abrams, F.: To Whom was the Anonymous „Lazarillo de Tormes“ dedicated? In: Romance Notes VIII (1966-67), S. 273-277. 
MEINE HERREN: Eines der Dinge, die mir Schwierigkeiten bereiteten, um das LEBEN DES PERIQUILLO SARNIENTO zu gebären, bestand darin, eine Person auszuwählen, der ich dieses Werk zueignen könnte, da ich schon unendlich viele Werke von geringem oder großem Verdienste gesehen habe, welche sich gleich zu Beginn mit ihren Widmungen schmückten. ${ }^{16}$

Dieser paratextuelle Auftakt ist erstaunlich: Schon zu Beginn des Textes weicht El Periquillo Sarniento von Normen und Selbstverständlichkeiten des damaligen ,Literaturbetriebs‘ ab. An die Stelle der Dedicatoria treten Reflexionen über die Sitte der Widmung, an die Stelle einer direkten Kommunikation und Ansprache an Auftraggeber beziehungsweise Mäzen tritt in der Folge ein Gespräch mit einem Freund. Dieser Dialog mit dem Freund situiert sich innerhalb der durch die epistolare Eröffnungsformel initiierten schriftlichen Kommunikationssituation.

Damit gelingt es Fernández de Lizardi, dem Paratext von Beginn an jene Struktur zu geben, die sich vereinfachend als Ineinander-Schachtelung verschiedener Kommunikationssituationen und -ebenen beschreiben lässt und dabei sowohl auf Formen der Mündlichkeit als auch der Schriftlichkeit zurückgreift. Grundlage hierfür ist die direkte Ansprache, der Dialog, der von Anfang an dazu dient, eine Idee in ihrer langsamen Verfertigung und Ausgestaltung vorzuführen.

Der Gedanke, die schwierige ,Geburt' dieses Textes im Lichte seiner Abweichung von vorgegebenen literarischen Regeln zum Thema des Prologs zu machen, ist indes hintergründiger, als dies auf den ersten Blick scheinen will. Denn das Frage- und Antwortspiel mit dem Freund blendet sogleich die soziale Situation des Schriftstellers, die materiellen Bedingungen des Literaturbetriebs wie etwa Druckkosten und Vertriebsmöglichkeiten, vor allem aber auch die nicht mehr nur individuelle Schwierigkeit ein, welche die schriftstellerischen Aktivitäten aller in Amerika Schreibenden betrifft: die Problematik, einen Adressaten, ein Publikum für die eigenen Werke zu finden. Kein nationaler literarischer Raum, kein Mäzen, kein „Vuestra Merced“ ist Partner in diesem Dialog, sondern ein kollektiver Adressat, jene „Señores míos“, die dem kolonialspanischen und nicht dem metropolitanen spanischen Raum zugehören. Der paratextuelle Raum gibt dieser spezifischen kolonialen (und zumindest perspektivisch einer unmittelbar postkolonialen) Situation konkreten literarischen Ausdruck und stellt ein Bekenntnis zur Situation des Schreibenden in Amerika dar:

„Ja, mein Freund“, sagte er ihm, ,und dies ist eine der größten Schwierigkeiten, welche die amerikanischen Talente gehabt haben und haben werden, um auf der literarischen Bühne

16 Fernández de Lizardi, José Joaquín: El Periquillo Sarniento. Prólogo de Jefferson Rea Spell. México: Editorial Porrúa ${ }^{11} 1970$, S. 1. 
so zu brillieren, wie sie es eigentlich müssten. Die hohen Kosten, die im Reiche der Druck gewichtiger Werke verursacht, halten viele davon ab, solche zu verfassen, zieht man in Betracht, wie sehr sie der Gefahr ausgesetzt sind, nicht nur keinen Preis für ihre Mühen zu empfangen, sondern vielleicht ihr ganzes Geld zu verlieren, wenn sie unveröffentlicht in den Regalen liegenbleiben wie so viele Kostbarkeiten, die dem Publikum Nutzen und ihren Autoren Ehre einbrächten. Dieses Unglück bewirkt, dass nicht ein einziges Werk von hier exportiert wird [..." $].^{17}$

Wir können uns die im weiteren Verlauf dieser Passage ausgeführte genaue Kalkulation der Kosten für Herstellung, Verschiffung und Verkauf des hier vorgestellten Werkes sparen: Für potentielle Käufer in Spanien käme in jedem Falle dieses Buch viel zu teuer. Für den in Amerika Schreibenden ist das spanische Publikum - und damit das „teatro literario“ - schlechthin unerreichbar. Was tun angesichts einer solchen Situation?

Es ergeben sich, wie der Prolog es andeutet, zwei Möglichkeiten: entweder das Verstummen aufgrund des zu hohen finanziellen Risikos oder die Erschließung neuer Leserschichten im kolonialspanischen Bereich. Damit bleibt der hispanoamerikanische Schriftsteller auf sein Lesepublikum in Amerika verwiesen - eine höchst unsichere Grundlage für das eigene Fortkommen. El Periquillo Sarniento trägt die Spuren dieser bewussten und dem Leser bewusst gemachten Entscheidung: Der intendierte (und auf absehbare Zeit einzig zugängliche) Leser des Romans lebt in den spanischen Kolonien Amerikas; wer ihn erreichen will, muss ihn finden und zu ihm sprechen.

Eine Analyse des Romans macht deutlich, dass eben dieses Publikum auch der implizite Leser ist, für den viele Latinismen, nicht aber die zahlreichen Mexikanismen übersetzt werden. ${ }^{18}$ Dass der reale Leser, an den sich der reale Autor Fernández de Lizardi mit einer Auflage von etwa fünfhundert Exemplaren wandte, diesem Vorhaben entsprach, wäre durch rezeptions- und lesersoziologische Untersuchungen erst noch zu belegen. Doch dürfte Fernández de Lizardis Strategie aufgegangen sein, darf er, der sich gegen Ende seines Lebens selbst als „escritor público“, ${ }^{19}$ als öffentlicher Schriftsteller, bezeichnete, doch als der wohl erste Berufsschriftsteller nicht nur Neuspaniens, sondern der hispanoamerikanischen Literaturen in ihrer Gesamtheit gelten. Aber wie hatte er dies geschafft?

17 Fernández de Lizardi, José Joaquín: El Periquillo Sarniento, S. 2.

18 Vgl. hierzu auch Cros, Edmond: Estructura testamentaria y discurso reformista en el „Periquillo Sarniento“ (México, principios del siglo XIX). In (ders.): Ideosemas y Morfogénesis del Texto. Literaturas española e hispanoamericana. Frankfurt am Main: Vervuert 1992, S. 124.

19 Vgl. hierzu ausführlich Franco, Jean: La heterogeneidad peligrosa: Escritura y control social en vísperas de la independencia mexicana. In: Hispamérica (Gaithersburg) XII, 34-35 (1983), insbes. S. $12 \mathrm{ff}$. 
Es verwundert nicht, dass das innerhalb der Novela picaresca stets zentral behandelte Thema des Geldes nicht erst auf Ebene der „histoire“, sondern bereits in der paratextuell inszenierten Dialogsituation eingeführt wird. Mit Hilfe dieses Kunstgriffs wird die finanziell stets ungesicherte Situation des Pícaro mit jener des Schriftstellers korreliert, der ähnlich wie der Protagonist des Schelmenromans ständig auf der Suche nach seinem Platz in der Gesellschaft ist. Dabei webt Fernández de Lizardi sogleich die transatlantische Dimension und die Möglichkeit eines gemeinsamen, Spanien und Hispanoamerika umgreifenden Literaturmarktes ein. Doch bis zur Verwirklichung einer solchen Ausbildung sollte noch viel Zeit vergehen; denn selbst heute stehen einem derartigen barrierefreien Markt noch immer Hindernisse entgegen.

Die Problematik des Berufsschriftstellers verwandelt den Paratext zu einem Bestandteil jenes „teatro literario“, das es in Spanisch-Amerika erst noch zu schaffen galt. Im Dialog der Freunde präsentiert sich uns eine Literatur, die ihre Adressaten, ihren eigenen Raum sucht und finden, ja erfinden muss. An diesem Punkt ist die interne mit der externen Kommunikationssituation des Paratextes verbunden und zugleich in ihrer textinternen Modellierung auf die textexterne, ,reale‘ Kommunikationssituation zugeschnitten. Ein Text sucht händeringend seine Leserschaft.

Doch geht es nicht um irgendeinen Text und irgendwelche Leser: Bereits die ersten beiden Seiten des Periquillo Sarniento zeigen, dass es sich bei dem ersten von einem Hispanoamerikaner in Hispanoamerika verfassten Roman um ein kulturelles Produkt handelt. Es wendet sich auf dem Markt symbolischer Güter an Leser in Hispanoamerika und tritt in Konkurrenz ebenso zu anderen Druckerzeugnissen neuspanischer und nicht-neuspanischer Provenienz wie auch zu weiteren kulturellen Erzeugnissen beziehungsweise Luxusgütern. Im Gespräch mit dem Freund werden etwa die enormen Aufwendungen der Adligen für Kutschen, Tänze, für das Glückspiel und andere Zerstreuungen als konkurrierende Ausgabenbereiche genannt. ${ }^{20}$

Als Publizist und Herausgeber des Pensador Mexicano hatte Fernández de Lizardi zuvor die Möglichkeiten, aber auch die Grenzen jenes diskursiven Raumes $^{21}$ erprobt, der sich nur kurzfristig auch in den spanischen Kolonien Amerikas im Gefolge der Verfassung von Cádiz vergrößert hatte. Die Verbüßung einer mehrmonatigen Gefängnisstrafe hatte Fernández de Lizardi aufgezeigt, wie

20 Fernández de Lizardi, José Joaquín: El Periquillo Sarniento, S. 2.

21 Vgl. hierzu auch die Überlegungen von Mora Escalante, Sonia Marta: Le picaresque dans la construction du roman hispano-américain: le cas du „Periquillo“. In: Etudes littéraires (Québec) XXVI, 3 (1993-94), S. 85. 
nachhaltig sich die Repräsentanten von Staat und Kirche gegen direkte Angriffe zu wehren wussten, wie sehr sie derartige Angriffe aber auch zu fürchten hatten, insoweit sich ein Publikum für journalistische Schriften gebildet hatte, das gesellschaftskritischen Ansichten offen gegenüberstand. Das Überwechseln von vorherrschend diktionalen zu vorherrschend fiktionalen Schreibformen, für das $E l$ Periquillo Sarniento steht, kommt einer erneuten Erprobung von Chancen und Tragfähigkeit des prekären Marktes für Druckerzeugnisse in Neuspanien gleich. Der Roman wird nicht allein als Erprobungsraum für neue und gesellschaftsverändernde Überlegungen genutzt, er dient auch als Experimentierfeld eines ökonomischen Versuchs in eigener Sache. Die Situation ist paradox: Fast schiene es, als ob sich ein Roman seinen Markt selbst erzeugen müsste und dies zum Thema seiner eigenen Schöpfung macht.

Doch sind Roman wie angepeilte Leserschaft gewiss keine Creatio ex nihilo. Seit Ende des 18. Jahrhunderts hatten in verschiedenen urbanen Räumen des spanischen Kolonialreichs in Amerika Periodika einen eigenen, wenn auch noch reduzierten Leserkreis geschaffen, der die Grundlage für die Ausbildung eines nationalen literarischen Marktes in den Kolonien selbst schuf. Lassen Sie mich kurz einfügen, dass eine nachdrückliche Vernetzung dieser verschiedenen nationalen Räume erst gegen Ende des 19. Jahrhunderts insbesondere mit den Zeitschriften der hispanoamerikanischen Modernisten erfolgte! Auch in Neuspanien hatte sich ein gewiss prekärer öffentlicher Raum für Periodika (mit seiner Leserschaft) herausgebildet, wie ihn nach den frühen Zeitschriften der zweiten Hälfte des 18. Jahrhunderts insbesondere der Diario de México zu Beginn des 19. Jahrhunderts nutzte und ausgestaltete. Dieser Leserschaft weiß sich Fernández de Lizardi verbunden, und ihr signalisiert er auch durch die paratextuelle und romaninterne Nennung des Pensador Mexicano, dass er genau hier - sozusagen vor den Toren der traditionellen „ciudad letrada“ des Vizekönigreichs ${ }^{22}$ - das direkt ansprechbare Publikum vermutete. ${ }^{23}$

Dies deutet bereits der ursprüngliche Titel des Werkes an: Vida de Periquillo Sarniento, escrita por él para sus hijos, y publicada para los que la quieran leer, por D.J.F. de L. autor del periódico titulado El Pensador Mexicano. Denn innerhalb des bestenfalls embryonal vorhandenen neuspanischen Marktes für novohispanische literarische Produkte konnte er als Herausgeber des nach Lockerung der Zensurbestimmungen 1812 begründeten und bis 1814 fortgesetzten El Pensador Mexicano darauf hoffen, durch die Bekanntheit seines Namens einen bestimmten Leserkreis insbesondere innerhalb der kreolischen Leserschaft anzusprechen und

22 Vgl. hierzu Rama, Angel: La ciudad letrada. Hanover: Ediciones del Norte 1984, S. 59. 23 Vgl. auch Vogeley, Nancy: Defining the „Colonial Reader“, S. 792. 
gezielt zu erreichen. Analog zur doppelten Kommunikationssituation des ersten Prologs wird damit bereits im ursprünglichen Titel eine Kommunikation auf zwei verschiedenen Ebenen angedeutet: textintern zwischen Periquillo Sarniento und seinen Söhnen, textextern zwischen jenen anonymen Lesern, die dieses Buch ,lesen mögen', und dem Verfasser des Pensador Mexicano, der sogleich den Roman in Beziehung zur journalistischen Produktion Fernández de Lizardis setzt. Ziel des neuspanischen Autors musste es daher sein, möglichst viele Leserinnen und Leser dazu $\mathrm{zu}$ bringen, sein Buch konsumieren $\mathrm{zu}$ wollen und mehr noch den in einzelnen Lieferungen, einzelnen „entregas“ gelieferten Roman käuflich zu erwerben. Denn wenn schon das kaufkräftige spanische Publikum wegfiel, so musste zumindest das neuspanische das Schreiben in Amerika finanziell unterstützen. Auch dies ist eine wesentliche Aufgabe der paratextuellen Ausstattung des Periquillo Sarniento, die nicht übersehen werden darf!

Es ist beeindruckend und lehrreich zugleich, wie das geschärfte Bewusstsein für die Bedingungen des eigenen Denkens, Schreibens und Publizierens in Neuspanien dieses Schreiben zugleich in das europäisch-amerikanische Spannungsfeld integriert. Spanien, unerreichbar für neuspanische Druckerzeugnisse und zugleich Monopolist der Buchimporte des kolonialspanischen Raums, wird einem spanischsprachigen Amerika gegenübergestellt, dessen Fähigkeiten auf Grund der kolonialen Asymmetrie brachliegen. Innerhalb dieses spanisch-hispanoamerikanischen Spannungsfeldes aber muss sich das Schreiben in Amerika notwendig bewegen und bewähren. Damit wird die größere Einheit deutlich, innerhalb derer die im Vorwort agierenden Figuren - das Ich, der Freund wie auch das angesprochene Publikum - handeln: (das spanischsprachige) Amerika. So wird in dieser „primera franca novela latinoamericana“, ${ }^{24}$ in diesem frank und frei ersten lateinamerikanischen Roman auch der hispanoamerikanische Raum als eigener Raum des Lesens und Schreibens skizziert.

Doch die Probleme überwiegen: Die ökonomische Situation des Berufsschriftstellers ist auf Grund seines fehlenden materiellen, und des prekären Wertes seines symbolischen Kapitals auf einem erst in Ansätzen vorhandenen literarischen Markt für eigene - das heißt: amerikanische - Erzeugnisse stets gefährdet. Dies macht der Dialog mit dem Freunde deutlich:

24 Rama, Angel: La ciudad letrada, S. 59. Zur Stellung des Romans im Gesamtwerk vgl. auch Meyer-Minnemann, Klaus: Apropiaciones de realidad en las novelas de José Joaquín Fernández de Lizardi. In: Dill, Hans-Otto / Gründler, Carola / Gunia, Inke / Meyer-Minnemann, Klaus (Hg.): Apropiaciones de realidad en la novela hispanoamericana de los siglos XIX y XX. Frankfurt am Main - Madrid: Vervuert 1994, S. 47-61. 


\begin{abstract}
„Ach, mein Seelenbruder! Du hast mir eine Ent-Täuschung beschert, aber zugleich eine tiefe Traurigkeit verschafft. Ja, Du hast mir die Augen geöffnet, indem du mir eine Portion Wahrheiten entgegengeschleudert hast, die unglücklicherweise unbestreitbar sind; und das Übelste ist, dass all dies darauf hinausläuft, dass ich meine Arbeit verliere; denn obwohl ich begrenzt bin und man daher von meinen Anstrengungen nichts Erhabenes, sondern nur Bescheidenes und Triviales erwarten kann, glaube mir, so hat mich doch dieses kleine Werk nicht wenig Arbeit gekostet, und dies umso mehr, als ich ein Chambón bin und ohne alle Hilfsmittel daran tätig war.“25
\end{abstract}

Das von Fernández de Lizardi entworfene schriftstellerische Ich steckt voller Widersprüche, die freilich gut begründet sind. Wenn es sich in dieser Passage auch als wenig kenntnisreicher und keineswegs zu sublimen Dingen fähiger Schriftsteller porträtiert - Wesensmerkmale eines literarischen Autors, wie sie auch das noch zu besprechende Selbstporträt gegen Ende des Romans plakatiert -, so erhebt es doch begründete Ansprüche auf Entlohnung seiner schriftstellerischen Bemühungen. Der hier ins Zentrum gestellte und von der Gesellschaft zu entlohnende Wert ist gerade für den „chambón“ (den wir als Autodidakten mit beschränkten Kenntnissen verstehen können) der Wert seiner Arbeit.

Verbunden mit dem Streben nach Verbesserung eben dieser Gesellschaft, für die der Schriftsteller nützlich ist, handelt es sich bei der Arbeit zugleich um jenen Wert, der auf Ebene der „histoire“ narrativ und auf Ebene der Kommentare und Digressionen diskursiv ständig als jenes Prinzip in Szene gesetzt wird, an dem sich eine künftige, noch zu schaffende bessere Gesellschaft zu orientieren habe. Schriftstellerische Arbeit tritt in dieser Passage an die Stelle von Schmeicheleien und Huldigungen innerhalb einer Ständegesellschaft, die den Autor nur in der Figur des Mäzens unterstützt und von ihm im Gegenzug Ehrerbietung und lobpreisende Widmungen zuhauf erwartet.

Worin aber besteht diese schriftstellerische Arbeit? Die Widmung des Werkes an ein keineswegs erlauchtes, sondern bunt zusammengewürfeltes Publikum eine Widmung, die mitunter den Tatbestand der Publikumsbeschimpfung erfüllt - gibt uns hierauf eine erste Antwort. Vergessen wir nicht: Publikumsbeschimpfung wie paratextueller Apparat stehen in einem dialogischen Verhältnis zu den umfangreichen Paratexten des intertextuellen Bezugstextes Guzmán de Alfarache, zu denen gemäß der literarischen Gepflogenheiten der Zeit nicht nur eine Widmung nebst Herrscherlob, sondern auch ein „vilipendio del vulgo“ zählte! Fernández de Lizardi hat in einer geistreichen Volte die Funktionen der bei Mateo Alemán voneinander getrennten Widmungen und Wendungen an einen Mäzen, an das niedere Volk und an den „discreto lector“ miteinander verbunden

25 Fernández de Lizardi, José Joaquín: El Periquillo Sarniento, S. 3. 
und zugleich dem niederen Volk und allgemeinen Publikum ebenso Widmung wie Leserorientierung zugedacht. Diese Rekontextualisierung und Resemantisierung konventioneller Schreibformen verweist auf Verfahren eines polylogischen intertextuellen Schreibens, das sich der Notwendigkeit spielerischer Aneignung und interkultureller Übersetzung bewusst ist. Bereits eine Untersuchung des Paratextes des Periquillo Sarniento macht die intertextuelle Relation zum Guzmán de Alfarache und damit zur Gattung des spanischen Schelmenromans überdeutlich.

Die schriftstellerische Arbeit besteht zuallererst in der Suche nach einem neuen Publikum und in dem Versuch, dieses nicht nur an das eigene Schreiben, an die Literatur heranzuführen, sondern gleichsam in dieses Schreiben zu verwickeln, Leser und Autor - und sei es nur auf Ebene der Fiktion - gemeinsam zu kompromittieren. Die Beziehungen zur vorbildgebenden spanischen Literaturtradition und damit die Einschreibung in den oben aufgeführten ersten Pol des kulturellen Spannungsgeflechts in Amerika sind evident:

Ich weiß sehr wohl, dass Ihr von einem Undankbaren abstammt und dass Ihr verwandtschaftliche Beziehungen zu den die Brüder mordenden Kains, zu den götzenanbetenden Nabucodonosors, zu den auf den Strich gehenden Dalilas, zu den sakrilegischen Balthasaren, zu den vermaledeiten Canes, zu den verräterischen Judas, zu den perfiden Sinones, zu den schurkischen Cacos, zu den ketzerischen Arriern und zu einer Masse an Pícaros und Pícaras habt, welche in derselben Welt wie wir gelebt haben und noch immer leben.

Ich weiß, dass Ihr zum Teil wohl Plebejer, Indios, Mulatten, Schwarze, Lasterhafte, Dummköpfe und Bekloppte seid.

Doch an nichts von alledem möchte ich Euch erinnern, zumal ich doch Eure wohlmeinende Unterstützung und Zuneigung gegenüber einem Werk erhalten will, welches ich Euch zueigne [...]. ${ }^{26}$

Wir müssen diese Publikumsbeschimpfungen mit den zeithistorischen, gesellschaftlichen und kulturellen Kontexten in Verbindung bringen, die im damaligen Neuspanien existierten. Im Kontext einer Gesellschaft, in der nur eine kleine Minderheit des Lesens kundig war, darf dieses Publikumsporträt nicht - wie dies freilich immer wieder geschah - wörtlich genommen und mit dem von Fernández de Lizardi tatsächlich erreichten realen Publikum gleichgesetzt werden. Nichts wäre irreführender und zugleich absurder! Doch leben all diese Spitzbuben, Indianer, Schwarze und Mulatten in eben jener Welt, in der sich das „nosotros“ des in den Plural wechselnden und mit „El Pensador“ signierenden Ich-Erzählers ansiedelt.

26 Fernández de Lizardi, José Joaquín: El Periquillo Sarniento, S. 3 f. 
Perspektivisch mag sich hier gerade mit Blick auf die indigene oder schwarze Bevölkerung ein künftiges Lesepublikum abzeichnen; das reale oder auch nur intendierte Publikum stellen die hier Angesprochenen jedoch gewiss nicht dar. Kein Zweifel: Das „nosotros“ wendet sich an eine alphabetisierte urbane kreolische Schicht, die seit dem Ausgang des 18. Jahrhunderts zur Trägerin der novohispanischen Aufklärung wurde! Diese neuspanische „Ilustración“, deren wichtige Existenz noch für einen Alexander von Humboldt eine Selbstverständlichkeit war, ist freilich heutzutage für unsere aufgeklärte Aufklärungsforschung eine weitgehende Terra incognita, weshalb wir im kommenden Semester einer „Aufklärung zwischen zwei Welten“, welche das Phänomen des „Siglo de las Luces“ nicht mit den bloß europäischen „Lumières“ verwechselt, unsere volle Aufmerksamkeit schenken wollen.

In El Periquillo Sarniento handelt es sich um eine neue Leserschaft, die sich außerhalb der „ciudad letrada“ und deren Konsekrationsmechanismen, außerhalb der Aulen und Hörsäle ${ }^{27}$ in einem doppelten Sinne gebildet hat. Die Vielfalt an Regionalismen beziehungsweise schichtenspezifischen sowie bestimmten ethnischen Gruppen eigenen Sprachmerkmalen, die in den Periquillo Sarniento Eingang fanden, darf uns nicht darüber hinwegtäuschen, dass es eine Ebene von Sprache und Stil gibt, die Autor und intendierter Leserschaft gemeinsam ist. Es handelt sich dabei weder um die Sprache der kulturellen Elite (der traditionellen „ciudad letrada“) noch um jene der urbanen Halbwelt. So erklärt der fiktive Herausgeber „Lizardi“ in Hinblick auf die von Pedro Sarmiento gewählte Stilhöhe: „Er schrieb sein Leben weder in einem kriecherischen noch in einem fertigen Stile nieder; er entflieht allem Gebildeten, verwendet einen häuslichen, familiären Stil, auf den wir alle im Allgemeinen zurückgreifen, in dem wir uns mit Leichtigkeit verstehen und verständlich machen.“28

Diese in den Paratext integrierte Aussage lässt weitgehende Schlüsse auf die Zielgruppe zu. Das angesprochene „Wir“ dieser Passage verbindet fiktiven Autor, fiktiven Herausgeber und intendierte Leserschaft miteinander und führt auf diese Weise eine Sprachgemeinschaft ein, die auf sprachlicher Gemeinsamkeit gründet und auf möglichst unbehindertes, direktes Kommunizieren und Verstehen abzielt. Wird in der Vielfalt verwendeter Sprachen im Roman eine virtuelle Nation in ihren Umrissen skizziert, so kommt der hiervon unterschiedenen Sprachgemeinschaft

27 Vgl. hierzu auch Franco, Jean: La heterogeneidad peligrosa, S. 13.

28 Fernández de Lizardi, José Joaquín: El Periquillo Sarniento, S. 463: „Escribió su vida en un estilo ni rastrero ni finchado; huye de hacer del sabio, usa un estilo casero y familiar, que es el que usamos todos comúnmente y con el que nos entendemos y damos a entender con más facilidad.“ 
von Autoren, Herausgebern und (möglicher) Leserschaft eine zentrale Rolle für die Kommunikation (und Führung) dieses (proto-)nationalen Raumes zu. So werden aus sprachlicher Perspektive die Umrisse eines künftigen Neuspanien, ja die Konturen des zukünftigen Mexiko sichtbar.

Gleichzeitig bildet diese Schicht nur den Kern eines möglichst breiten und in seiner Heterogenität der Erzählerfigur des Vorworts bewussten Lesergemeinde, der dieses Werk vielleicht nicht unmittelbar zugänglich, immerhin aber zugeeignet ist. Vom „gusto“ dieser Käuferschicht hängen „los autores, impresores, papeleros, comerciantes, encuadernadores y demás dependientes“ ${ }^{\text {29 }} \mathrm{ab}$, also die gesamte Maschinerie des Buch- und Pressebereiches. Die Silhouette eines neuen Literatursystems mit neuen Konsekrationsinstanzen zeichnet sich ab. El Periquillo Sarniento belegt in seiner materiellen Existenz die Entstehung dieses neuen Raumes, der mit literarischen Mitteln fiktional abgesteckt wird.

In dem diesem ersten Vorwort unmittelbar folgenden „Prólogo de Periquillo Sarniento“ gelangen wir von der externen paratextuellen zur internen paratextuellen Ebene. Ich möchte Ihnen anhand der präzisen Untersuchung dieses Romans aufzeigen, wie wichtig Vorworte, Widmungen oder Motti und Nachworte für ein tieferes Verständnis von Literatur sind und möchte damit der Warnung Gérard Genettes beipflichten: „Attention au paratexte!“

Die im ursprünglichen Titel des Romans angekündigte doppelte Kommunikationssituation wird insoweit eingelöst, als es nun die Figur Periquillo Sarnientos selbst ist, die sich zu Wort und an seine unmittelbaren und mittelbaren Leserinnen und Leser wendet. Diese spezifische Kommunikationssituation ist selbst wiederum zweigeteilt, insoweit sie sich explizit auf zwei verschiedene Adressaten bezieht: zum einen die direkte Wendung des Vaters an seine Kinder, zum anderen die Anrede einer Leserschaft, die über diese erste Kommunikationssituation hinaus durch die Weitergabe des Manuskripts erreicht werden könnte. Ist der externe paratextuelle Raum als „Schwelle“ (im Sinne Genettes ${ }^{30}$ ) zwischen textexternem und textinternem Bereich aufzufassen, so handelt es sich hier offenkundig um einen paratextuellen Raum, der unverkennbar textintern organisiert und Teil der Fiktion ist. Diesem Raum wollen wir uns nun zuwenden!

Dies bedeutet nicht etwa, dass im Gegensatz zu Periquillo Sarniento die das erste Vorwort unterzeichnende Instanz („El Pensador“) eine reale textexterne Gestalt wäre. Auch sie ist nicht anders als der Pícaro selbst eine vom realen Autor Fernández de Lizardi geschaffene literarische Figur. Doch sind ihr textextern referentialisierbare Attribute beigestellt, welche diese Instanz des Vorworts zu einer

29 Ebda., S. 4.

30 Genette, Gérard: Seuils. Paris: Seuil 1987. 
für Paratexte typischen, zwischen textexternem und textinternem Bereich oszillierenden, im Text selbst angesiedelten Schwellenfigur machen. Mit dem realen Autor verwechseln dürfen wir auch sie freilich nicht, auch wenn uns - und dieses Verfahren ist so alt wie die neuzeitliche Literatur selbst - der Autor in seiner Fiktion immer wieder mit seinen Autornamen angeht. Vorsicht also bei Autornamen - und nicht nur, wenn der ,postmoderne“ Jorge Luis Borges eine seiner Figuren „Borges“ tauft!

Dementsprechend führen wir eine deutliche Namensregelung ein und unterscheiden um der Klarheit willen zwischen dem auf Ebene der erzählten Zeit angesiedelten Pícaro und dem auf jener der Erzählzeit situierten, seinem Lebensende nahen Erzähler. Den ersteren belegen wir mit seinem ihm zugelegten Spitznamen Periquillo Sarniento und den letzteren mit seinem am Anfang und Ende des Romans genannten ,bürgerlichen' Namen Pedro Sarmiento. ${ }^{31}$ So zeigt sich deutlich, dass die Instanz dieses zweiten Vorworts jene Erzählerfigur auf Ebene der Erzählzeit ist, die uns aus der gattungstypischen rückschauenden Perspektive die Lebensgeschichte berichtet. Die unmittelbaren und ausdrücklich im Text genannten Adressaten - und damit der explizite Leser - dieses Lebensberichts sind die Kinder, für die allein kein Vorwort nötig gewesen wäre. Doch könnte diese „Vida“ auch in andere Hände fallen, und so zeigt sich, dass gerade für diesen in seinen Grenzen unklar bleibenden Leserkreis ${ }^{32}$ eine paratextuelle Situierung („una especie de Prólogo“) 33 des nachfolgenden Textes vonnöten ist.

Die bewusst offen gehaltene Leserschaft, die durch den nachfolgenden Bericht belehrt und unterhalten werden soll und in ihren Konturen die anonyme Leserschaft des ersten Vorworts intradiegetisch verlängert, wird mit der hintersinnigen Behauptung Pedro Sarmientos konfrontiert, dass nichts „ficción de mi fantasía“ sei und daher auch kein Grund bestehe, an meiner Wahrheit, an „mi verdad“ zu zweifeln. ${ }^{34}$ Wir befinden uns hier in einem Raum, in welchem sich Spiegel wechselseitig reflektieren und ihre Wahrheit, ihre Perspektive zu lesen geben.

31 Diese Trennung ließe sich in gewisser Weise mit jener zwischen Alonso Quijano und Don Quijote vergleichen. Zu den Beziehungen zwischen Fernández de Lizardi und Cervantes vgl. Lasarte, Pedro: Don Catrín, Don Quijote y la picaresca. In: Revista de Estudios Hispánicos (St. Louis) XXXIII, 3 (1989), S. 101-112; sowie González Cruz, Luis F.: El Quijote y Fernández de Lizardi: revisión de una influencia. In: Criado de Val, Manuel (Hg.): Cervantes: su obra y su mundo. Actas del I Congreso Internacional sobre Cervantes. Madrid: EDI 1981, S. 927-932.

32 Fernández de Lizardi, José Joaquín: El Periquillo Sarniento, S. 6: „aun cuando todo el mundo lea mi obra.“

33 Ebda., S. 5.

34 Ebda., S. 5. 
Damit aber wird die Leserschaft noch nicht in den ,eigentlichen` Text entlassen. Vielmehr dient das zweite Vorwort in struktureller Hinsicht als eine Art Schleuse zwischen externem und internem Paratext. Denn nun werden innerhalb des fiktionalen Raums des Romans „Advertencias generales a los lectores“ präsentiert, die die konkrete Textgestalt als Ergebnis der Arbeit eines kommentierenden, ergänzenden, streichenden, stilistisch umarbeitenden und den Text mit Anmerkungen versehenden Herausgebers darstellen. Aus der Schwellenfigur des Pensador ist damit ein intradiegetischer Editor geworden, der von Pedro Sarmiento unmittelbar vor den seinem Lebensbericht nachgestellten „Notas del Pensador“ als „un tal Lizardi“, ${ }^{35}$ als ein gewisser Lizardi, in den Romantext als Figur eingeführt wird. Auch diese Figur darf selbstverständlich nicht mit dem realen Autor gleichen Namens verwechselt werden, was innerhalb der Forschungsliteratur des Öfteren jedoch nicht berücksichtigt wurde. ${ }^{36}$ Wir wollen diese Figur im weiteren Verlauf unserer Untersuchung einfach „Lizardi“ nennen.

Diese Instanz ist logischerweise befugt, Pedro Sarmiento als „nuestro autor ${ }^{\text {*37 }} \mathrm{zu}$ bezeichnen und eine gewisse Problematisierung der moralisierenden Exkurse vorzunehmen. Die Erlaubnis für alle Eingriffe in den Text habe ihm der mit ihm freundschaftlich verbundene Autor selbst gegeben. Damit wird deutlich: Auf Ebene der Fiktion ist „Lizardi“ der erste kritische Leser des Lebensberichts Pedro Sarmientos, dessen (Lebens-)Ende er selbst als intradiegetischer Augenzeuge miterlebt hat. Seine Arbeit und Aufgabe ist die eines zugleich Lesenden und Schreibenden, so dass sich der Leser nun mit einer recht komplexen Modellierung von Stimmen konfrontiert sieht, die zu ihm sprechen: Pedro Sarmiento, der Verfasser des Lebensberichts, „Lizardi“ als dessen fiktiver Herausgeber und schließlich „El Pensador“ als um sein schriftstellerisches Überleben in der neuspanischen Gesellschaft ringender Autor. All diese Figuren sind selbstverständlich das Werk des realen José Joaquín Fernández de Lizardi, der die einzelnen Figuren (so etwa auch die Leserfiguren) miteinander in ausführliche Dialoge verwickelt. Wir dürfen feststellen, dass die Komplexität dieser Anlage sich mit so erfolgreichen Herausgeberfiktionen wie in Cervantes' Don Quijote oder Rousseaus Julie ou La Nouvelle Hélö̈se ohne weiteres messen kann und selbst hinter der komplizierten Konzeption mancher postmoderner Fiktionen nicht zurückstehen muss.

35 Ebda., S. 453.

36 So findet sich selbst in der vergleichsweise differenzierten Studie Nancy Vogeleys die Behauptung, Fernández de Lizardi habe sich damit als Herausgeber selbst in den Text eingeführt (vgl. Defining the „Colonial Reader“, S. 793). Auch sie übersieht damit die für eine Analyse des Romans grundlegende Scheidung von textexternem und textinternem Bereich.

37 Fernández de Lizardi, José Joaquín: El Periquillo Sarniento, S. 7. 
Ich kann an dieser Stelle nicht auf die Tatsache eingehen, dass ein längeres Zitat aus dem Vorwort von Jamins 1776 in Paris erschienenem Le fruit de mes lectures - einem Werk, das Zitate griechischer und römischer Autoren enthält, von denen viele in El Periquillo Sarniento Eingang fanden - die Kommunikationsstrukturen wie auch die Autorenposition in ihrer Komplexität noch weiter erhöht. Doch erweist sich bei der Untersuchung des paratextuellen Raums die im Bachtin'schen Sinne verstandene Vielstimmigkeit von Fernández de Lizardis Roman zunächst auch ohne Einbeziehung des spezifisch intertextuellen Raums - gerade bei einem Romanerstling - als beeindruckend. Dass Fernández de Lizardi mit seinem paratextuellen Verwirrspiel auch hohe Anforderungen an seine Leserschaft stellte, versteht sich von selbst und mag erklären, warum dieser Roman nie wirklich populär werden konnte.

Die auf Ebene der fiktiven Herausgeberfigur „Lizardi“ angesiedelte Inszenierung editorischer Tätigkeit in einem weiteren, zwischen erstem und zweitem Teil angesiedelten „Prólogo en traje de cuento“ (Prolog im Gewand einer Erzählung), stellt dies einmal mehr unter Beweis. So sehen wir nicht nur den Herausgeber zunächst alleine zu Hause bei der Arbeit, „mit der Feder in der Hand und damit beschäftigt, die Seiten dieses Bändchens mit Anmerkungen zu versehen“. ${ }^{38}$ Wir bemerken auch erneut, dass nach der Ansprache an den „señor lector“ diese Kommunikationssituation von einem Dialog unterbrochen wird, in welchem sich der (fiktive) Herausgeber mit einem Freund namens „Conocimiento universal“ über den bisherigen Erfolg des Periquillo Sarniento beim Lesepublikum unterhält. ${ }^{39}$

Dabei handelt es sich um Selbstverständigungs- und Selbstreflexionstexte, die stets mit einem gewissen Humor ausgestattet sind. Die Heterogenität des Publikums - „das Publikum sind alle oder niemand“; es bestehe aus „Gebildeten wie aus Dummköpfen“ ${ }^{\star 40}$ - wird dabei ebenso thematisiert wie erste recht unterschiedliche Leserreaktionen auf die zuvor gelieferten und verkauften Kapitel des Romans. Deutlich wird hieran nicht nur, wie sich die einzelnen Figuren von den verschiedenen Kommunikationsebenen her dieselben Stichworte zuwerfen, sondern auch, wie sehr die Selbstbezüglichkeit dieses Textes dessen literarischästhetische Modernität ausmacht. Denn am Ende dieser Inszenierung der Herausgeberfigur verwandelt sich diese in eine Autorfigur, welche das als Erzählung verkleidete Vorwort zum zweiten Teil mit einer Wendung an den Leser abschließt. Dergestalt vertauscht sie die Feder des Herausgebers mit der eines Autors: „Ich ergriff die Feder und schrieb unsere Konversation nieder, damit Sie, mein Leser

38 Ebda., S. 187: „,con la pluma en la mano anotando los cuadernos de esta obrilla.“

39 Ebda.

40 Ebda.: „el público es todos y ninguno“; „sabios“ wie aus „,necios“. 
und Freund, Geschmack daran finden und die Geschichte des berühmten Periquillo weiterlesen“. ${ }^{41}$

Das Lesepublikum sieht so bei der Entstehung des Textes zu, den es vor Augen hat. Der distanzierte anonyme Leser ist zu einem Freund geworden, der die Geschichte Periquillos lesend weiterverfolgen soll: Der „amigo lector“ ist der Käufer der nachfolgenden Kapitel und damit zu jener Figur avanciert, die das literarische Spiel überhaupt erst in Gang setzt und in Gang hält. Im Roman selbst ist er jedoch nur eine unter mehreren Leserfiguren. Er bildet - dies macht der Blick ins Atelier deutlich - als Käufer einen notwendigen Bestandteil des textintern entworfenen Literaturbetriebs; nicht mehr, aber auch nicht weniger!

Am Ende des fünfzehnten Kapitels des dritten und letzten Teils übergibt - wie bereits angedeutet wurde - der dem Tode nahe Pedro Sarmiento dem zu seinem Freunde gewordenen neuspanischen Journalisten Lizardi, der auch als „Pensador Mexicano“ bezeichnet wird, zu treuen Händen das Manuskript seines Lebensberichts mit der Bitte, es zu bearbeiten und mit Anmerkungen zu versehen. Zuvor aber findet er noch Zeit und Gelegenheit, diesen Freund namens Lizardi zu porträtieren, einen ,in Ihrem Vaterland glücklosen Schriftsteller und beim Publikum bekannt“. ${ }^{22}$ Dabei soll uns weniger dieses Selbstbildnis Fernández de Lizardis interessieren, das auch selbstkritische Züge enthält und den Roman gleichsam signiert, als jene kleine Bemerkung, die abschließend die Beziehung zwischen „Lizardi“ und Pedro Sarmiento erläutert: „Wir haben uns so sehr geliebt, so dass ich sagen kann, dass ich mit dem Pensador ein Einziges bilde und er mit mir“. ${ }^{43}$

Diese Bemerkung Pedro Sarmientos transgrediert offenkundig die Herausgeberfiktion und schließt in unmittelbarem Anschluss an das Selbstbildnis die verschiedenen Ebenen autobiographisch kurz. Die in dieser wichtigen Passage behauptete Identität der beiden Romanfiguren wird noch dadurch verstärkt, dass „Lizardis“ erstes Wort dem kranken Freunde gilt: „Bis hierher schrieb mein guter Freund Pedro Sarmiento, den ich liebte wie mich selbst““. ${ }^{44}$ Es ist ein literarischer und erzähltechnischer Kurzschluss mit Folgen: Denn damit nimmt „Lizardi“ nicht nur das Manuskript, sondern auch den Erzählfaden selbst in die eigenen schriftstellerischen Hände, was zum einen die Kontinuität des Erzählvorgangs sicherstellt, zum anderen die paratextuelle Rahmung des Gesamtwerks im Nachhinein

41 Ebda., S. 189: „yo tomé la pluma y escribí nuestra conversación, para que usted, amigo lector, haga boca y luego siga leyendo la historieta del famoso Periquillo.“

42 Ebda., S. 453: „escritor desgraciado en vuestra patria y conocido del público.“

43 Ebda., S. 454: „tanto nos hemos amado que puedo decir que soy uno mismo con el Pensador y él conmigo.“

44 Ebda.: „Hasta aquí escribió mi buen amigo don Pedro Sarmiento, a quien amé como a mí mismo." 
zusätzlich legitimiert. Schließlich schafft dies die romantechnischen Voraussetzungen dafür, dass die Lebensgeschichte des Pedro Sarmiento von der Geburt bis zum Tode prinzipiell lückenlos dargestellt werden kann.

Aus all diesen Punkten ergibt sich eine gewisse Transgression des architextuellen Grundschemas, also jenes Schemas, das die gattungsspezifische Verortung des Romans angeht. El Periquillo Sarniento schreibt sich, wie wir sahen, von Beginn an in das Gattungsschema der Novela picaresca ein, also des Schelmenromans. $\mathrm{Zu}$ den gattungskonstitutiven erzähltechnischen Voraussetzungen hierfür zählt die Trennung zwischen einem erzählten und einem erzählenden Ich, wobei des ersteren Leben und Abenteuer in mehr oder minder chronologischer Abfolge aus der Perspektive eines zur Ruhe gekommenen, ,reiferen“ oder ,bekehrten' Ich dargestellt werden, das seinen Platz in der Gesellschaft (wenn auch nicht immer widerspruchslos und -frei) gefunden hat.

Die erzähltechnisch logische Konsequenz dieser strukturellen Anlage ist ein ständig kleiner werdender Abstand zwischen der Ebene der erzählten Zeit und jener der Erzählzeit, für El Periquillo Sarniento mithin die Spanne zwischen 1771 beziehungsweise 1773 (dem Zeitpunkt der Geburt) und 1813 (dem Jahr der Übergabe des Manuskripts und des Todes Don Pedros). Fallen beide Zeitebenen miteinander zusammen, so sind wir am Ende der „histoire“ angekommen, also jener Summe chronologisch verfügbarer Erzählbausteine, die für die Anordnung durch eine Erzählerfigur bereitgestellt sind, nicht aber am eigentlichen Lebensende dieses Erzählers selbst, der von seinem eigenen Tod nur schwerlich berichten kann. Beispiele hierfür lassen sich in anderen literarischen Gattungen, meines Wissens aber nicht im Schelmenroman finden.

Die strukturelle Anlage des Lazarillo de Tormes - eines narrativen Textes, der sich ebenfalls als „Vida“ präsentiert - legt als Ausgangsmodell späterer erzähltechnischer Variationen hiervon beredtes Zeugnis ab. Die im Periquillo Sarniento ebenfalls gattungskonform übernommene Trennung zwischen der Mobilität des erzählten Ich und der Statik des erzählenden Ich - eine Ökonomie, auf die noch zurückzukommen sein wird - bleibt ebenfalls bis zur Übergabe der Manuskriptseiten an den fiktiven Herausgeber gewahrt. Dieser Übergabe aber schließen sich gleichsam paratextuell die bereits erwähnten „Notas del Pensador“ sowie das sechzehnte und letzte Kapitel des Buches an, in welchem aus der Perspektive „Lizardis“ Tod und Bestattung des Pedro Sarmiento dargestellt werden, Ereignisse, die - so die Kapitelüberschrift - „den Leser bei der Hand nehmen und zum Ende dieser höchst gewissen Geschichte führen“. ${ }^{45}$

45 Fernández de Lizardi, José Joaquín: el Periquillo Sarniento, S. 460: „llevan al lector por la mano al fin de esta ciertísima historia.“ 
Dieser literarische Kunstgriff erlaubt es, auf wenigen Seiten innerhalb des Romans nicht nur das Ineinander-Fallen (wenn auch nicht die Fusion) von erzählter Zeit und Erzählzeit, von erzähltem Ich und erzählendem Ich, von Periquillo Sarniento und Pedro Sarmiento - und nicht umsonst sind beide Namen auf dem Grabstein verewigt - vor Augen zu führen. Er ermöglicht zugleich, das Gattungsschema des Schelmenromans, wie es der Lazarillo de Tormes vorgab, unter Rückgriff auf eine andere literarische Gattung zu erweitern, die den neuspanischen, vom Katholizismus geprägten Leserinnen und Lesern zu Beginn des 19. Jahrhunderts wohlvertraut war: die Form der Heiligenviten. Sie erst ermöglicht den Zugriff auf ein gesamtes Leben von der Geburt bis zum Tode; ein Zugriff, der dem Menschen bezüglich seines eigenen Lebens verwehrt ist, sind dem individuellen Bewusstsein doch weder die eigene Geburt noch der eigene Tod zugänglich. Dies bewirkt und vermag allein die Literatur!

Sie springt in die Bresche und ermöglicht die Verfügbarkeit eines gesamten Lebens von dessen Anfang bis zu dessen Ende, wobei der durch diese Verfügbarkeit (und Verfügungsgewalt) erzielte Lustgewinn bei hagiographischen Schreibformen gleichsam ideologisch bezahlt werden muss durch die Einreihung dieses individuellen Lebens in transzendente heilsgeschichtliche Zusammenhänge. Pedro Sarmiento macht gegenüber seinen Söhnen sein eigenes Leben zum „Exemplum“; doch kann die Einordnung in ein transzendentes Schema erst dadurch gelingen, dass auch sein Sterben in seiner Sinnhaftigkeit dargestellt wird und so dem Lesepublikum als sinnhafte Einheit erscheinen kann.

José Joaquín Fernández de Lizardi griff auf dieses Schema der exempelhaften Heiligenviten zurück, modifizierte es aber nicht nur erzähltechnisch, indem er diese Rolle nicht einem extradiegetischen, sondern einem intradiegetischen Erzähler übertrug, sondern wandelte es auch ideologisch ab, indem er sein Bezugsmodell desakralisierte und nicht mehr in heilsgeschichtliche, sondern historische und historiographische Zusammenhänge einband. So wird ein Leben beispielhaft für eine Gesellschaft, deren Säkularisierung und Modernisierung fernab aller theologischen Prämissen eingefordert wird. Allein eine historische Rekontextualisierung etwa hinsichtlich der revolutionären Ereignisse und Aufstände im gärenden Neuspanien, auf die der Roman explizit anspielt, ${ }^{46}$ konnte aber nicht genügen. Fernández de Lizardi musste daher eine weitere Gattungsform mit dem Grundmuster der Novela picaresca verbinden.

Die Ersetzung heilsgeschichtlich-transzendentaler Sinnangebote erforderte die zumindest perspektivisch angelegte Einbeziehung zukunftsbezogener Ent-

46 Nehmen wir den „Prólogo en traje de cuento“ ernst, so reicht die Romandiegese bis ins Jahr 1816, also dem sukzessiven Erscheinen der einzelnen Teile des Periquillo Sarniento. 
wicklungsmodelle, die freilich erst in den letzten Teil des Romans, nachdem der Pícaro die gesellschaftlichen Möglichkeiten des kolonialspanischen Herrschaftssystems erprobt und letztlich erfolglos ausgeschöpft hatte, eingeführt werden konnten. Als generisches Modell einer solchen kritisch auf die eigene Gegenwart gemünzten Zukunftsvision wählte der neuspanisch-mexikanische Autor die Form der Utopie in ihrer ,klassischen“ Ausprägung. Er griff dabei auf Vorstellungen Platons und Aristoteles', auf Caussins La Cour sainte und Fénelons Télémaque, ${ }^{47}$ vor allem aber auf Thomas Morus' Utopia und damit auf ein Raummodell, nicht aber auf das Zeitmodell der Uchronie zurück. Letzteres hatte Louis-Sébastien Mercier wenige Jahrzehnte zuvor in seinem L'An deux mille quatre cent quarante 1771 ins Werk gesetzt und damit die Form der modernen Utopie wesentlich mitgeprägt. ${ }^{48}$ Es bedarf an dieser Stelle keinerlei Mühe, einerseits die Belesenheit des neuspanischen Autors in den abendländischen Literaturen, andererseits aber auch seine entschiedene Einschreibung in diesen ersten Pol des transatlantischen kulturellen Spannungsfeldes anzuerkennen.

Gleichviel, ob wir das 18. Jahrhundert in Europa als goldenes Zeitalter der Utopien oder als Krisenzeit der literarischen Utopie verstehen, auffällig ist doch, dass sich der mexikanische Schriftsteller nur an der räumlichen, nicht aber an der zeitlichen Projektion und deren literarischer Filiation orientierte. Dabei blendete er in starker Gattungskonformität all jene Elemente ein, die von Schiffbruch und Inselsituation über statische Stadt- und Gesellschaftsordnung bis hin zu streng reglementierten Arbeits- und rigorosen Bestrafungsformen reichten. Damit setzte er seinen eigenen utopischen Entwurf zum kanonischen Modell des Thomas Morus in eine enge intertextuelle sowie architextuelle Beziehung.

47 Vgl. hierzu Hudde, Hinrich: Fernández de Lizardi. Literarische Utopie an der Schwelle der Unabhängigkeit Mexikos (mit Bemerkungen zu modernen lateinamerikanischen Utopien). In: Literaturwissenschaftliches Jahrbuch der Görres-Gesellschaft N.F. 27 (1986), S. 253-267, sowie speziell zu der grundlegende Vorstellungen Lizardis prägenden Beziehung zum Télémaque Strosetzki, Christoph: Fénelon et Fernández de Lizardi: De l'absolutisme au libéralisme. In: Oeuvres et Critiques (Tübingen) XIV, 2 (1989), S. 117-130.

48 Zweifellos ein wenig voreilig bezeichnete Raymond Trousson Mercier als „père de l'utopie moderne“; vgl. R.T.: Introduction. In: Mercier, Louis-Sébastien: L'An deux mille quatre cent quarante. Rêve s'il en fut jamais. Bordeaux: Editions Ducros 1971, S. 61. Eine nuanciertere bzw. kritischere Sichtweise der Rolle Merciers geben Krauss, Henning: Der Ursprung des geschichtlichen Weltbildes, die Herausbildung der „opinion publique“ und die literarischen Uchronien. In: Romanistische Zeitschrift für Literaturgeschichte (Heidelberg) XI, 3-4 (1987), S. 337-352, sowie Kuon, Peter: Utopie et anthropologie au siècle des lumières ou: la crise d'un genre littéraire. In: Hudde, Hinrich / Kuon, Peter (Hg.): De l'Utopie à l'Uchronie. Formes, significations, fonctions. Actes du colloque d'Erlangen 16-18 octobre 1986. Tübingen: Gunter Narr Verlag 1988, S. 49-62. 
Dies bedeutet keineswegs, dass es sich bei Fernández de Lizardis Entwurf um eine literarische ,Imitation“ oder gar um ein Plagiat handeln würde. Zum einen ist der Aufenthalt Periquillos auf der Insel Sancheofú die wohl erste literarische Utopie innerhalb der lateinamerikanischen Literaturgeschichte und daher per se eine epochemachende Innovation, welche man gar nicht stark genug als literarisches Verdienst herausstreichen kann. Zum anderen stellt die Projektion der Utopie von Hispanoamerika aus in den Westen auch insoweit eine grundlegende Neuerung, ja einen Bruch mit der europäischen Tradition dar, als nicht mehr Amerika für die europäischen Autoren die leere Leinwand für deren eigene Projektionen abgab. ${ }^{49}$ Asien und der pazifische Raum rückten nunmehr in den Blick der angehenden, wenn auch noch nicht als solche $\mathrm{zu}$ bezeichnenden Lateinamerikaner.

Die Entscheidung Fernández de Lizardis für die spezifisch utopische und damit gegen die noch junge uchronische Tradition, welcher ebenso literarhistorisch wie auch bezüglich der in ihr angelegten Historisierung politisch-gesellschaftlicher Gegenentwürfe eine hohe revolutionäre Potenz zukam, darf nicht aus heutiger Perspektive als ideologisch rückschrittlich missdeutet werden, weil sie sich etwa an einem statischen Geschichtsbild orientiert hätte. Gewiss ist nicht von der Hand zu weisen, dass eine statische Vision der Geschichte, wie sie sich innerhalb der an Utopia von 1516 anschließenden literarisch-philosophischen Tradition oftmals beobachten lässt, auch dem Utopie-Kapitel des Periquillo Sarniento nicht fremd ist. Doch dürfen wir diese ästhetisch meiner Ansicht nach überzeugende Lösung nicht als Zeichen einer wie auch immer gearteten rückwärtsgewandten ideologischen Orientierung des neuspanisch-mexikanischen Autors deuten, sondern müssen begreifen, welche Erkenntnispotentiale der paradox auf den Raum bezogenen U-topie innerhalb des gesellschaftlichen Projekts Fernández de Lizardis zukamen. Hierzu gilt es, die topographische Dimension des von Fernández de Lizardi in seinem Roman ausgespannten nationalen Raumes zu erfassen.

Zuvor aber sollten wir in der gebotenen Kürze unsere Analyse des architextuellen Raumes in El Periquillo Sarniento abschließen. Dabei stoßen wir zunächst auf die in den Text integrierten lyrischen Formen, die zumeist intradiegetisch verankert sind und von der Lizardi-Forschung kaum einmal beachtet wurden. Paradigmatisch hierfür scheinen mir jene ,décimas“ zu sein, die Periquillo unmittelbar nach einem gescheiterten Selbstmordversuch niederschreibt. Er hatte sich nach seiner glücklichen Rückkehr von der utopischen Insel nach Mexiko einmal

49 Vgl. hierzu Cerutti Guldberg, Horacio: Utopía y América latina. In (ders.): Presagio y tópica del descubrimiento. México: CCYDEL 1991, S. 21-33. Dabei erstaunt, dass in dieser in Mexiko vorgelegten Arbeit der utopische Entwurf von Fernández de Lizardi unerwähnt bleibt. 
mehr Lebensformen des Adels und damit nicht dem bürgerlichen Wert der Arbeit verpflichtet gefühlt, war aber bald schon in die urbane Halbwelt abgestiegen. Er hätte sich nach schmachvollen Erlebnissen selbst ins Jenseits befördert, wäre das von ihm gewählte Verfahren der Selbsttötung nicht zu umständlich und ungeschickt gewesen. Selbst die Techniken des Selbstmords wollen gelernt sein! Doch schließlich ist auch das gelungene Scheitern eines Suizidversuches ein in seiner Widersprüchlichkeit ernstzunehmendes Statement.

Durch dieses Scheitern gelangt der Pícaro zur lyrischen Erkenntnis des „Du musst Dein Leben ändern“, eine Bewusstwerdung, die nachhaltig nur in der Form der Lyrik erfolgen zu können scheint und zugleich Züge des Lehrgedichts trägt. Als Nachahmung spanischer „décimas“ kann ich Ihnen diesen Textauszug in seiner deutschen Übersetzung freilich nicht bieten:

Lernet, Ihr Menschen, von mir, / Was von gestern zu heute war; / Noch gestern war ich Graf und Wesir, / Doch heut' bin ich aller Ehren bar. / / Nicht einer lebe getäuscht / Und glaube, dass das Glück / Wenn günstig ein ganzes Stück, / Ohne sein Antlitz zu kehren. / Lebet alle voller Sorge, / Ein jeder schaue für sich, / Das Schicksal ist wankelmütig / Und wendet sich rasch wie es will: / Ich bin ein wandelnd Exempel: / Drum Lernet, Ihr Menschen, von mir. / / Wohl weiß ich's, Chimären sind's, / Die Geldsäck, die nur auf sich pochen, / Wohl gibt es glückliche Epochen, / Ihr mögt sie nennen, wie’s Euch gefällt. / Wüsste ich eifrig zu nutzen / Eine von diesen, so wär's gewiss, / Ich ginge nicht, wie Ihr mich seht; / doch verachtete ich das Glück, / und seh' mich nun im Unglück: / Was von gestern zu heute war! / / Gestern noch war ich ein Ritter / Von hell strahlender Gestalt, / Und seh' mich doch heute ganz klein, / In Lederhosen mein Gebein. / Gestern noch hatt' ich viel Geld; / Doch heut' hab' ich nicht einen Taler, / Bewein mich in all meiner Trauer, / Mein' Hochmut ich heute bedauer, / Denn war ich auch eingebildet, / Noch gestern war ich Graf und Wesir. / / In dieser sich wendenden Welt / War ich gestern Arzt und Soldat, / Barbier und Winkeladvokat, / Küster und Apotheker. / Mönch war ich und Sekretär, / Und bin ich heute auch arm. / Kaufmann auf Reisen ich war, / Ein Gstudierter mit Abitur. / Doch ich Ärmster, dieses ward gestern, / Doch heut' bin ich aller Ehren bar. ${ }^{50}$

An diesem noch von Periquillo und noch nicht von Pedro Sarmiento niedergeschriebenen Gedicht interessiert uns nicht die intertextuell bemerkenswerte Tatsache, dass es sich hier um eine freie Anverwandlung von Versen Góngoras handelt, auf die bereits Lope de Vega zurückgegriffen hatte. Auch mag für die Fragestellung unserer Vorlesung die architextuell sicherlich signifikante Erkenntnis nur nachgeordnete Bedeutung besitzen, dass sich an dieser Passage zeigt, dass die Gattung des Romans auch in Hispanoamerika von Beginn an fähig war, andere Gattungen in sich aufzunehmen und auf diese Weise sich weitere literari-

50 Fernández de Lizardi, José Joaquín: El Periquillo Sarniento, S. 401. 
sche Traditionsstränge anzueignen und einzuverleiben. Denn noch bedeutungsvoller scheint mir, dass in diesem Lehrgedicht, dessen wiederkehrender Vers „Aprended, hombres, de mí das eigentliche didaktische Leitmotiv des Romans beziehungsweise des Lebensberichts Don Pedros enthält, die Grundelemente der „histoire“ dem Leser wie dem Schreibenden selbst kopräsent vor Augen geführt und wie in einem gewaltigen textuellen Brennspiegel fokalisiert werden. Das Lehrgedicht verdichtet fundamentale Isotopien des Schelmenromans. Dieser Verdichtungsprozess der lyrischen Form allein führt noch nicht zur rettenden Wende, verweist aber auf ein geschärftes Bewusstsein des Protagonisten, das unabdingbare Voraussetzung für die den Lebensbericht abschließende „,conversión“ ist. Zugleich markiert dieses Poem wie die anderen in Periquillo Sarniento abgedruckten Gedichte einen Ruhepunkt innerhalb der Bewegungen des Textes und des Lesens, auf deren hermeneutische Dimension noch zurückzukommen sein wird.

Weitere in den Roman integrierte Gattungen, die innerhalb des gesamten Textes eine wesentlich größere Ausdehnung als die Lyrik erreichen, betreffen nicht-fiktionale, nicht-narrative Schreib- und Ausdrucksformen, von denen insbesondere wissenschaftliche Abhandlung, theologisches Traktat, Predigt und Essay zu nennen sind. Der Roman verleibt sich damit Gattungen ein, die unterschiedlichste Formen nicht-fiktionaler und nicht-erzählender Prosa darstellen, welche ihrerseits fiktional und narrativ gerahmt werden. Sie stehen zum narrativen Text in einem eigenartigen Spannungsverhältnis, das bereits in den „Advertencias generales a los lectores“ thematisiert wurde, nachfolgenden Leserinnen und Lesern aber bis heute die größten Schwierigkeiten bei der Lektüre zu machen scheint.

Diese Schreibformen bilden das Gros der sogenannten ,Digressionen“ und ,moralisierenden Abschweifungen', die Fernández de Lizardis Roman immer wieder zum Vorwurf gemacht wurden: Sie würden die Handlung nicht vorantreiben und zugleich den Lesefluss mit allerlei unnützem Ballast beschweren, so dass der Roman insgesamt an gängiger Lesbarkeit verliere. Dieses Spannungsverhältnis zwischen dominant fiktionalen und nicht-fiktionalen Teilen des Romans soll uns am Ende unserer Analyse nochmals beschäftigen. Bereits jetzt aber darf man festhalten, dass der hier aufgezeigte Einbau unterschiedlichster Gattungen und Schreibformen Fernández de Lizardis Roman eine überaus heterogene, ja disparate Textur vermittelt, die dank ihrer ungeheuren Flexibilität und Integrationsfähigkeit der als generatives Grundmuster dienenden Novela picaresca ausgebildet werden konnte. Ist der Roman also doch überladen und leidet unter einem Ballast, der notwendig jeden Fortgang der Handlung verlangsamt?

Der architextuelle Raum des Periquillo Sarniento weist eine für den spanischen Schelmenroman so ungewöhnliche Heterogenität auf, dass deren Ursa- 
chen in den Spezifika eines in Amerika angesiedelten Schreibens aufgesucht werden müssen. Vergessen sollten wir dabei nicht, dass es Fernández de Lizardi in seinem Periquillo Sarniento gelang, mit lyrischen und essayistischen Formen just jene Gattungen in den Roman zu integrieren, denen Angel Rama eine gewisse epistemologische Priorität innerhalb der hispanoamerikanischen Literaturen einräumte.

Periquillos „décimas“ bringen im Rückgriff auf spanische, aber schon seit der Antike präsente Formeln die gesamte soziale Spannbreite der Gesellschaft des Vizekönigreichs Neuspanien zum Ausdruck. Die Berufe und sozialen Rollen, die Perico innerhalb dieser vermeintlich festgefügten Ständegesellschaft ausgefüllt und mehr recht als schlecht gespielt hat, reichen vom Adligen und Arzt über Klosterbruder und Küster bis hinunter zum Tagelöhner und Taschendieb, Bettler und Blinden, Falschspieler und Frauenschänder: Die gesamte neuspanische Gesellschaft der Zeit ersteht vor unseren Augen in verdichteter Form.

In völliger Konformität mit der Gattungstradition quert Periquillo in seiner Eigenschaft als Pícaro verschiedene soziale Stände und Berufe, von der Verwaltungsspitze der neuspanischen Elite über die Welt der Offiziere und Gerichtsschreiber, der lasziven Adligen und braven Bürger bis hinunter in die Halbwelt der Verbrecher und Prostituierten, der sozial Ausgegrenzten und Verelendeten. Auch die ethnische Heterogenität der neuspanischen Gesellschaft wird in ihrer vollen Breite wahrhaft durchlaufen: Periquillo hat es mit Indianern und Mestizen, mit Schwarzen, Mulatten und Kreolen, mit aus Spanien stammenden „gachupines“, ja mit Vertretern eingewanderter Gruppen nicht-hispanischer Provenienz wie Angelsachsen, Franzosen und geradezu prophetisch sogar mit einem Chinesen $\mathrm{zu}$ tun. Letzterer wird es freilich bald wieder vorziehen, auf seine utopische Insel zurückzukehren und auf einen Besuch Europas und anderer Weltteile zu verzichten. Denn das neuspanische Beispiel zeige ihm doch zur Genüge, was ihn andernorts erwarten werde.

Insgesamt handelt es sich im Periquillo Sarniento um das literarische Fresko einer Gesellschaft, die von extremer Heterogenität, gleichzeitig aber auch von einem hohen Grad an Abgeschlossenheit geprägt ist, welche sich erst unter dem Einfluss handeltreibender nicht-spanischer Nationen aufzulösen beginnt. Der urbane Raum - und damit nicht zufällig auch die „ciudad letrada“ mit ihren für den Roman erreichbaren Leserschichten - steht vom ersten Augenblick an im Zentrum von Pedro Sarmientos Lebensbericht:

Ich wurde in Mexiko geboren, der Hauptstadt des Nördlichen Amerika, in Neuspanien. Keinerlei Lobessprüche aus meinem Munde wären ausreichend, um sie meinem lieben Vaterlande zu widmen; zugleich wären sie eben darum auch verdächtig. Diejenigen, die dieses Land bewohnen, und die Ausländer, die es gesehen haben, können sein Loblied mit grö- 


\begin{abstract}
ßerer Glaubwürdigkeit vortragen, insofern es bei ihnen keinen störenden Effekt einer Parteilichkeit gibt, deren Vergrößerungsglas bisweilen die Defekte maskiert oder die Vorzüge des Vaterlandes mitunter selbst für die dort Geborenen als größer erscheinen lässt; indem ich so die Beschreibung von Mexiko den unparteiischen Neugierigen überlasse, sage ich: dass ich in dieser reichen und dicht bevölkerten Stadt in den Jahren 1771 oder 1773 auf die Welt kam und zwar als Kind von Eltern, die nicht im Überflusse lebten, aber auch nicht aus dem Elend stammten; zugleich waren sie von reinem Blute, das sie auf Grund ihrer Tugend erstrahlen ließen und bekannt machten. Ach, wenn nur immer die Kinder beständig den guten Beispielen ihrer Eltern folgten! ${ }^{51}$
\end{abstract}

Mit Stolz wird der eigene Geburtsort, die Stadt Mexiko, als Hauptstadt nicht Neuspaniens, sondern Nordamerikas angegeben. Das ist geographisch absolut korrekt, liegt Mexiko doch in geographischer Hinsicht - wie Ihnen ein Blick auf die Landkarte zeigen kann - in Nordamerika. Am Ausgang des 18. Jahrhunderts gab es gute Gründe, die eigene Zentralität zu betonen und - im Anschluss an aztekische wie vizeköniglich-neuspanische Vorstellungen - Mexiko als Kapitale zu begreifen. Noch war nichts von einer Übermacht der Vereinigten Staaten im Norden zu hören. Mexiko-Stadt war freilich die Hauptstadt eines Territoriums, das von größter Heterogenität und Hybridität geprägt war und noch lange nicht zu einem Staatswesen im modernen Sinne zusammengewachsen war. Und genau diesen laufenden Nationenbildungsprozess, diesen „Nation Building Process“, stellt der Roman mit großer Sorgfalt dar.

Die bereits beobachtete soziale wird in El Periquillo Sarniento in der Folge durch eine starke topographische Vielgliedrigkeit des neuspanisch-mexikanischen Territoriums ergänzt. Innerhalb Mexikos - und darunter wird gleich zu Beginn des Romans nicht etwa eine Nation oder das Vizekönigreich, sondern ein als „mi cara patria“ aufgefasster städtischer Raum, eben jener der Hauptstadt des neuspanischen „Virreinato“ verstanden - stehen sich von unterschiedlichen sozialen Klassen genutzte beziehungsweise für bestimmte Gruppen vorgesehene Räume geradezu unversöhnlich gegenüber. Sie werden nur durch die ständigen Bewegungen des Pícaro miteinander verbunden.

Schon aus diesem Blickwinkel erscheint die Figur des (neu-)spanischen ,Schelms‘ als all diese relativ autonom voneinander strukturierten Räume allein verbindende Gestalt. Den Vierteln der Adligen, in denen Periquillo als Dienstbote oder Faktotum, mitunter aber auch als Neureicher und ,falscher‘ Edelmann wohnt, stehen jene Gefängnismauern gegenüber, in denen Vertreter der gesellschaftlichen Elite oder des Bürgertums kaum einmal anzutreffen sind. Kein Wunder also, dass ein Weißer, findet er sich in dieser Gesellschaft der ,indios,

51 Fernández de Lizardi, José Joaquín: El Periquillo Sarniento, S. 12. 
castas, negros, lobos“ und „mulatos“ wieder, rasch zum „blanco“, zur Zielscheibe wird..$^{52}$ Dies ist umso mehr der Fall, als der junge Mann nicht bereit ist, seinen aus der „limpieza de sangre“, der im obigen Zitat unterstrichenen Blutreinheit, familiär ererbten und abgeleiteten Herrschaftsanspruch jemals aufzugeben, seiner realen und stets prekären sozialen Lage zum Trotz. Zu groß ist der von ihm interiorisierte Dünkel, aus einer blutreinen weißen Familie zu stammen. Er konnte noch nicht ahnen, dass er nur ein Jahrhundert später bei der Einreise in die USA ganz wie die katholischen Iren seinen Status als „non-white“ und zusätzlich als „latino“ hätte ankreuzen müssen. ${ }^{53}$

Die gesamte neuspanische Gesellschaft ist eine noch immer weitgehend statische Stände- und Kastengesellschaft, die erst in einigen wenigen Bereichen durchlässiger und mobiler zu werden beginnt. Selbst der Raum des Gefängnisses ist als Modell und mehr noch Fraktal der gesamten Gesellschaft anzusehen. Er ist in sich differenziert, warten doch hinter der Gesellschaft sozial Deklassierter und einfacher Krimineller die berüchtigten Gefängnismauern von San Juan de Ulúa an der Karibikküste oder des Morro im nicht allzu weit entfernten Havanna, das zum damaligen Zeitpunkt noch Mexiko-Stadt unterstellt war. Auch in der Hauptstadt der Ausgegrenzten und Inhaftierten finden sich metropolitane Herrschaftsstrukturen auf der topographischen Ebene wieder, die gesamtgesellschaftlich wie gefängnisintern vermittelt werden. Es wäre sehr wohl möglich, den verschiedenen städtischen Räumen die Stadt der Gefangenen entgegenzustellen und als eine Art Gegen-Stadt zu untersuchen, ja aus dieser Perspektive der insulären Utopie einen anderen utopischen Raum als fraktalen Zerrspiegel entgegenzuhalten. Doch muss eine Untersuchung, die diese Gegen-Stadt zugleich als Symbol der kolonialen Stadtgesellschaft und als ethisch-soziale Gegenutopie lesbar machen könnte, an dieser Stelle zurückgestellt werden. Das Gefängnis ist nicht nur der Ander-Ort einer Heterotopie, sondern auch der Nicht-Ort einer konkreten Utopie, deren Grundstrukturen freilich die Gesamtgesellschaft spiegeln.

Die von Beginn an signalisierte Bezogenheit auf die Hauptstadt Mexiko zeigt es: Dem urbanen stellt sich der rurale Raum krass entgegen. Auf den ersten Blick scheint es keine Vermittlung zwischen „ciudad“ und „campo“ zu geben. Eine Verbindung zwischen beiden ist nur insoweit gegeben, als Periquillo mit einer gewissen Vorliebe auch die äußeren Stadtviertel, Vororte und vor den Toren der Hauptstadt gelegenen Dörfchen und Landgüter besucht und durchstreift. Stets aber bleibt der Pícaro letztlich der Hauptstadt verbunden und zugehörig.

52 Ebda., S. 174.

53 Vgl. hierzu Painter, Nell Irving: A History of White People. New York - London: W.W. Norton 2009. 
Dabei bildet der diese Hauptstadt des Vizekönigreichs umgebende geographische Raum zugleich den Fluchtraum ursprünglich urbaner, nun aber aus dem städtischen Leben ausgegrenzter Gruppen und Figuren, die als Diebe, Scharlatane oder korrupte Verwaltungsangehörige seine Gegenden durchstreifen und unsicher machen. Eine eingehendere Analyse könnte aufzeigen, dass diese weiten Landgebiete zwar als relativ autonome Bereiche erscheinen, letztlich aber nicht als eigenwertige kulturelle Räume aufgefasst werden, sondern negativ als jene Welt definiert sind, die der Stadt (und damit ist letztlich immer Periquillos Geburtsstadt gemeint) negativ gegenübertritt.

Die Dichotomie von Stadt und Land ist dabei nicht in der Art von Sarmientos später zu untersuchendem Facundo im Gegensatzpaar Zivilisation versus Barbarei modelliert, wenn sich auch bestimmte Parallelen bezüglich der Abwertung nicht-urbaner Räume aufzeigen ließen. Die Landgebiete und Provinzen Neuspaniens bilden vielmehr relativ autarke Räume, die keineswegs einen Herrschaftsanspruch gegen das städtische Zivilisationsmodell erheben und dergestalt der abendländischen Zivilisation ein anderes ,kulturelles‘ Modell entgegenstellen. Sie verharren vielmehr in ihrer Abgeschlossenheit und sind nur über bestimmte zumeist korrupte Vertreter kolonialspanischer Verwaltung sowie der kirchlichen Organe an die Hauptstadt und über diese an die Metropole angeschlossen.

So käme es Periquillo Sarniento niemals in den Sinn, die von ihm durchstreiften ländlichen Bereiche als kulturelle Räume sui generis aufzufassen oder gar in ihnen kulturelle Modelle zu erblicken, welche zu jenem der Hauptstadt in Konkurrenz treten könnten. Sie sind für ihn Räume einer ,Unkultur‘. Als Hauptstädter sieht er in den Provinzen wenig mehr als binnenkoloniale Erweiterungsund Ergänzungsräume, welche vorrangig der Nutzung und Ausplünderung durch die Hauptstadt dienen. Selbst dem distanzierter urteilenden Pedro Sarmiento erscheinen die Landgebiete nicht in ihrer kulturellen Eigenständigkeit oder gar die verschiedenen indianischen Kulturen als wirkliche zivilisationstragende Hochkulturen im abendländischen Sinne. Wie die schwarzen Kulturen in der Karibik sind sie im 18. und über weite Strecken des 19. Jahrhunderts als kulturelle Pole noch ausgeblendet.

Und doch blitzen auch in diesen Darstellungen der nicht-städtischen Räume immer wieder Elemente einer kulturellen Heterogenität und Autarkie auf, bezahlen die Indianer den als Arzt verkleideten städtischen Kreolen doch nicht mit Geld, sondern in Naturalien, was auf die räumliche Begrenztheit monetärer Zahlungsmittel innerhalb des neuspanischen Kolonialraumes schließen lässt. Auch eine dritte Instanz, die des intradiegetischen Herausgebers, scheint auf den ersten Blick nicht bereit, den Kulturen der indigenen Bevölkerung einen eigenständigen Status zuzuerkennen oder in ihnen gar einen wichtigen kulturellen Pol zu erblicken. So lesen wir in einer Fußnote „Lizardis“: 
Es gibt noch immer Dörfer, in denen die Indios für ihre Toten ein Itacate bereitstellen, eine Art Säckchen mit allerlei Dingen zum Essen nebst einigen Münzen. In anderen Dörfern verstecken sie für sie darüber hinaus ein Papier, das voller Unsinn ist für den Ewigen Vater, und ihre Weihegaben folgen demselben Aberglauben. An einem anderen Orte werden wir sagen, wer die Menschen sind, die solche Missbräuche unterstützen. ${ }^{54}$

Indianische Sitten und Gebräuche werden hier als „abusos“, als „disparates“ und „superstición“ abqualifiziert: Ihnen wird keinerlei kultureller Status zuerkannt. Dennoch zeigt sich bei genauerer Betrachtung, dass die Wahrnehmung kultureller Alterität zumindest ambivalent ist, werden diese Sitten doch kontextuell mit Totengebräuchen der abendländischen Antike in Verbindung gebracht, da Pedro Sarmiento unmittelbar zuvor betont hatte, dass sich die Sitte der Wegzehrung auch dort bei den großen Kulturvölkern finde. ${ }^{55}$

In der angeführten Passage fällt dem intradiegetischen, also fiktionalen Herausgeber mithin eher die Aufgabe zu, eine womöglich als zu stark aufwertende Äußerung zu indianischen Kulturen augenfällig zu relativieren. Die Anmerkung des fiktiven Herausgebers verweigert zwar derartigen Riten bei den Indianern jegliche kulturelle Anerkennung, liefert zugleich aber jene Elemente, welche die indianischen Gebräuche mit denen der Totenbräuche von Griechen und Römern auf eine Stufe stellen. So zeigt sich an dieser freilich eher Ausnahmecharakter besitzenden Stelle, wie subtil das Zusammenspiel zwischen der Erzählergestalt Pedro Sarmiento und der mit ihr befreundeten Herausgeberfigur namens „Lizardi“ sein kann.

Dieser „Lizardi“ macht - wie andeutungsweise auch am Ende dieser Fußnote auf seine anderen Schriften aufmerksam und verweist bisweilen darauf, ähnliche Vorschläge etwa zum Schulsystem bereits in seinem Periodikum El Pensador Mexicano vorgelegt $\mathrm{zu}$ haben. ${ }^{56}$ Die intradiegetische Herausgeberfigur versucht also immer wieder, sich selbst mit textextern referentialisierbaren Attributen auszustatten, um eine Identifizierung mit dem realen Autor Fernández de Lizardi zu provozieren. Doch sollten wir uns hüten, diese textinterne Figur mit dem realen Autor zu verwechseln! Wir haben es vielmehr mit einem subtilen Spiel zwischen verschiedenen Perspektiven zu tun, wobei aufschlussreich ist, dass Elemente kultureller Alterität im Text mit wachsender Distanz zur Ebene der erlebten Zeit (also zum unmittelbaren Erleben Periquillos) deutlicher als solche wahrgenommen werden können. Der Tatbestand einer den gesamten Text durchziehenden Dar-

54 Fernández de Lizardi, José Joaquín: El Periquillo Sarniento, S. 99.

55 Ebda.

56 Vgl. ebda., S. 112. 
stellung fundamentaler Heterogenität im gesamten neuspanischen Kolonialraum bleibt freilich bestehen.

Neuspanien ist auf dem widerspruchsvollen Wege, zu einem Mexiko zu werden, das den unruhigen Zeiten des 19. Jahrhunderts standhalten könnte. Doch eine Gewissheit gibt es dafür nicht. Die mehr oder minder ausgedehnten Reisen Periquillos über Land sind letztlich keine Reisen durch verschiedene Kulturen, sondern durch disparate Räume, die es kulturell an die Hauptstadt des Vizekönigreichs erst noch anzuschließen und zu modernisieren gilt. Zugleich spannen sie den territorialen Raum einer sich abzeichnenden künftigen Nation aus. Karibikwie Pazifikküste, Norden und Süden des Landes, ja selbst die zum Vizekönigreich Neuspanien gehörenden Philippinen werden im Roman erfasst, wobei es Fernández de Lizardi gelingt, angesichts der beschränkten Reisemöglichkeiten der Zeit die Romandiegese dadurch immer wieder zu erweitern, dass andere Romanfiguren nicht-städtischer Herkunft ihre Geschichte erzählen. Auf diese ästhetisch überzeugende Weise werden auf Ebene der romanesken Handlung immer wieder andere Regionen Neuspaniens in die Romandiegese eingeblendet, also in die raumzeitliche Welt des Periquillo Sarniento - dem Gebote der Wahrscheinlichkeit folgend - integriert, so dass nahezu der gesamte denkbare Raum eines künftigen Neuspanien oder Mexiko literarisch dargestellt werden kann.

Damit wird eine Einheit in Vielfalt erkennbar, die freilich erst in nuce den nationalen Raum eines künftigen Nationalstaats umschreibt. Wir haben es mit einem protonationalen Mexiko zu tun. Man könnte El Periquillo Sarniento in Bezug auf diesen sich herausbildenden nationalen Raum als einen Roman des Übergangs zwischen kolonialspanisch und nationalstaatlich strukturierten Herrschaftsräumen bezeichnen. Herrschaftsräume und binnenkoloniale Ergänzungsräume sind sie nicht zuletzt insoweit, als andere als zentralisierte politische Strukturen in El Periquillo Sarniento nicht ins Bild gerückt werden. Einmal mehr ist der Pícaro jene literarische Figur, welche die verschiedenen auseinanderstrebenden Teile des in Entstehung begriffenen Staatsgebildes romandiegetisch zusammenhält und miteinander kommunizieren lässt.

Die Gestalt des Pícaro ist dabei weniger auf der Inhaltsebene, etwa als Symbolfigur nationaler Identitätssuche, ${ }^{57}$ denn als erzähltechnisch-konstruktive

57 Daher scheinen mir auch Interpretationsansätze, welche zu verstehen versuchen, wie Periquillo Sarniento als nationale Identitätsfigur hätte wirken sollen, in die Irre zu führen. Jaime Torres Bodet etwa deutete den Periquillo gar als nationale Identitätsfigur und stellte ihn auf eine Ebene mit Argentiniens Martín Fierro: Torres Bodet, Jaime: Estudio preliminar a José Joaquín Fernández de Lizardi. In: Fernández de Lizardi, José Joaquín: El Pensador Mexicano. México 1962, S. vii; vgl. hierzu auch Skirius, John: Fernández de Lizardi y Cervantes, S. 259 f. 
Voraussetzung der Schaffung eines pränationalen Raumes zu begreifen. Nicht über die Aneignung einer wie auch immer gestalteten symbolhaften Figur und hierzu würde sich jene in der spanischen literarischen Tradition verankerte Gestalt des Pícaro gewiss wenig eignen -, sondern über die erzähltechnisch und inhaltlich erfolgende Vernetzung konstituiert sich Nationales in diesem hispanoamerikanischen Roman. Versuchen wir daher, in diesem Zusammenhang den kulturellen wie den literarischen Raum näher zu untersuchen!

Fernández de Lizardis Protagonist bewegt sich nicht nur in den drei Dimensionen des topographischen und geographischen Raumes, sondern auch in jenen der Zeit und der sozialen Hierarchie der zumindest tendenziell in ihrer gesamten Breite und Schichtung porträtierten Gesellschaft. ${ }^{58}$ Darüber hinaus befindet sich der Pícaro aber auch in den Dimensionen literarischer Tradition und Filiation sowie in jener anderen der interkulturellen Beziehungsgeflechte. Ohne an dieser Stelle auf alle im ersten Band der Reihe „Aula“ behandelten Dimensionen von Literatur eingehen zu können, seien doch die für unseren Fragehorizont wichtigen und bedeutungsbildenden Ebenen hervorgehoben!

Bezieht man den Roman in seiner Gesamtheit auf die zumindest fünf ersten für diesen Zeitraum zu unterscheidenden kulturellen Pole, so zeigt sich rasch, dass sich El Periquillo Sarniento in den ersten Pol der vorbildgebenden iberischen Kultur im Kontext ihrer abendländischen Traditionsstränge einschreibt. ${ }^{59}$ Dies ist der den Roman beherrschende Pol. Die verschiedenen indigenen Kulturen werden, wie das „todavía“ in der oben zitierten Fußnote des fiktiven Herausgebers anzeigt, wohl in das kulturelle Kräftefeld eingeblendet, in ihrer Permanenz aber negiert und als Kulturraum entweder nicht wahrgenommen und ausgeschieden oder aber marginalisiert. Ähnlich ergeht es dem dritten Pol, jenem der schwarzen Kulturen, auch wenn wie bei den Indianern einzelne Individuen herausgestellt und mit positiven Zügen versehen werden. So gerät etwa ein wortgewandter schwarzer Kaufmann aus Jamaica zum Vertreter nicht etwa der kulturellen Eigenständigkeit schwarzer Kulturen, sondern zum Sprachrohr logozentrischer abendländischer Positionen. In deren Namen wird von ihm jene Sozialkritik und vernichtende Anklage der Sklaverei vorgetragen, die dazu führten, dass die neuspanische beziehungsweise kolonialspanische Zensur eingriff und ein Erschei-

$58 \mathrm{Zu}$ den verschiedenen Dimensionen der in einem literarischen Text stattfindenden Bewegungen vgl. die vorgängige Vorlesung von Ette, Ottmar: ReiseSchreiben. Potsdamer Vorlesungen zur Reiseliteratur. Berlin - Boston: Walter de Gruyter (Reihe Aula, 1) 2020.

59 Vgl. hierzu Ette, Ottmar: Asymmetrie der Beziehungen. Zehn Thesen zum Dialog der Literaturen Lateinamerikas und Europas. In: Scharlau, Birgit (Hg.): Lateinamerika denken. Kulturtheoretische Grenzgänge zwischen Moderne und Postmoderne. Tübingen: Gunter Narr Verlag 1994, pp. $300 \mathrm{f}$. 
nen dieses Teiles des Romans untersagte. So musste 1816 die Erstausgabe aller Lieferungen des Periquillo Sarniento noch Fragment bleiben.

Formen kultureller Hybridisierung sowie Mischformen, wie sie von der „ciudad letrada“ negiert worden waren, tauchen im Roman in verschiedenen Ausprägungen sehr wohl auf. Doch wird ihnen ebenso wenig eine kulturelle Vorbildfunktion eingeräumt wie den Volkskulturen iberischer Provenienz, die in der Darstellung insbesondere urbaner Alltagskultur in Form von Sprichwörtern, Spielen, Kleidungsformen und vielem mehr einen breiten Raum einnehmen. Betrachten wir das in El Periquillo Sarniento ausgespannte kulturelle Feld in seiner Gesamtheit, so fällt überdies auf, dass zu den genannten fünf ersten Polen unseres Schemas ein weiterer hinzukommt, der uns in der Gestalt des aufgeklärten Chinesen entgegentritt. Es ist spannend zu sehen, dass dieser Pol asiatischer Kultur - wie wir vorhin bereits bei Chimalpahin bemerkten - im damaligen Neuspanien durchaus präsent war, war Neuspanien doch etwa seit dem 17. Jahrhundert zu einem Zentrum der Namban-Kunst und der Namban-Malerei geworden, ${ }^{60}$ die mit der Vertreibung von Malern aus Japan begann, welche nach europäischer Tradition unter Einsatz perspektivischer Darstellungen malten. Es gibt folglich durchaus eine historisch sehr lange und keineswegs nur bis in die pazifische Ausdehnungsphase des zeitgenössischen China zurückreichende asiatische Präsenz in Mexiko.

Freilich handelt es sich in El Periquillo Sarniento um eine in der kulturellen Utopie der Insel Sancheofú verankerte literarische Projektion, der weniger die Funktion ,alternativer‘ kultureller Modellbildungen für ein künftiges Mexiko zukommt als jene andere, eine Position zu befestigen, von der aus es möglich wird, gleichsam von außerhalb nun der novohispanischen und mit ihr der spanischen Gesellschaft einen Spiegel entgegenzuhalten. In der Figur des Chinesen treten uns also nicht Elemente der chinesischen Kultur, sondern bestimmte diskursive Strategien und literarische Verfahren entgegen, wie sie seit Beginn des 18. Jahrhunderts insbesondere die französische Aufklärung etwa in den Lettres Persanes entwickelt hatte. Damit aber wird der Chinese paradoxerweise und

60 Vgl. hierzu Rivero Leke, Rodrigo: Namban Art in Viceregal Mexico. México: Estilo México Turner 2005; Ocaña Ruiz, Sonia: Mother-of-Pearl Inlaid Frames: The Use of Japanese Ornamental Models in New Spanish Paintings. In Pierce, Donna / Otsuka, Ronald Otsuka (Hg.): Asia and Spanish America: Trans-Pacific Artistic and Cultural Exchange 1500-1850. Denver: Denver Art Museum 2009, S. 129-149; Takizawa, Osami / Míguez Santa Cruz, Antonio (Hg.): Visiones de un Mundo Diferente. Política, Literatura de avisos y Arte Namban. México: Centro Europeo para la Difusión de las Ciencias Sociales 2015; sowie Ette, Ottmar: Muebles movibles y pintura en movimiento: los biombos y las fronteras ajustables de lo transareal. In: Iberoamericana (Madrid Frankfurt am Main) XIV, 54 (junio de 2014), S. 85-95. 
zugleich zum Vertreter des ersten Pols der vorbildgebenden abendländischen Traditionsstränge. Betrachten wir daher diesen Pol noch etwas genauer!

Kulturelle Optionen in einem vollen Wortsinn sind in dieser neuspanischen Novela picaresca stets als schriftkulturell sich äußernde Positionen markiert. Damit bewegt sich Fernández de Lizardi innerhalb der Tradition novohispanischer Aufklärung und auf dem Boden der „ciudad letrada“, wenn er auch durch geschickte Übertragung des Gattungsmodells des spanischen Schelmenromans eine gesellschaftliche Totalität darzustellen vermag, in welcher gerade auch die marginalen und marginalisierten Elemente des „Virreinato“ (von einer außerhalbbefindlichen Position aus) darstellbar werden. Der Pícaro durchläuft die gesamte Spannbreite der damaligen Gesellschaft und ermöglicht dank seiner mobilen Perspektivik deren panoramaartige Darstellung.

Die Ausrichtung des kulturellen Raumes an schriftkulturellen Ausdrucksformen ermöglicht es, das interkulturelle Beziehungsgeflecht auf der Ebene vorbildgebender kultureller Optionen im Wesentlichen als intertextuellen beziehungsweise literarischen Raum zu erfassen und darzustellen. ${ }^{61}$ Die für das Schreiben in kolonialspanischen Kontexten bis zu jenem Zeitpunkt dominante Ausrichtung an der spanischen Literatur- und Philosophietradition scheint sich dabei auf den ersten Blick auch in El Periquillo Sarniento wiederfinden zu lassen, schreibt sich der Roman doch - wie wir sahen - in großer Gattungskonformität in die spanische Tradition des Schelmenromans ein. Innerhalb dieser Tradition ließe sich im Sinne Francisco Ricos überdies ausmachen, dass Fernández de Lizardi dabei auf jene Filiation zurückgriff, die sich vom anonymen Lazarillo de Tormes und Mateo Alemáns Guzmán de Alfarache, nicht aber etwa von Quevedos Vida del Buscón herleitet. ${ }^{62}$

Merkmale dieser Filiation innerhalb der Novela picaresca wie etwa die Entwicklung des Protagonisten vom „actor“ zum „autor“, die sogenannte „novelización del punto de vista“ oder die damit zusammenhängende Ausrichtung an der Perspektive des innerlich umgewandelten, ,konvertierten' Pícaro sind ausnahmslos Elemente, die sich auch in Fernández de Lizardis Romanerstling finden. Sie lassen sich aber auch in Alain-René Lesages Gil Blas de Santillane ausmachen, der es verstanden hatte, diese, spanische“ Gattungsform - wenn auch nicht diegetisch - auf Frankreich zu übertragen und, mehr noch, diskursiv gegenüber früh-

61 Zur Begrifflichkeit vgl. Ette, Ottmar: Dimensiones de la obra: iconotextualidad, fonotextualidad, intermedialidad. In: Spiller, Roland (Hg.): Culturas del Río de la Plata (1973-1995). Transgresión e intercambio. Frankfurt am Main: Vervuert Verlag 1995, S. 13-35.

62 Vgl. hierzu Rico, Francisco: La novela picaresca y el punto de vista. Barcelona: Seix Barral ${ }^{4} 1989$. 
aufklärerischen Vorstellungen und Schreibformen zu öffnen. So bildet Lesages Gil Blas de Santillane ein überaus wichtiges intertextuelles Bindeglied zwischen der spanischen Novela picaresca und deren Übersetzung in neuspanische Kontexte, wobei sich nicht nur in der Figur des schwarzen Kaufmanns Züge erkennen lassen, die wiederum Guillaume-Thomas Raynals Histoire des deux Indes entlehnt sind.

Es kann an dieser Stelle nicht darum gehen, das ungeheuer reiche und vielfältige intertextuelle Netzwerk darzustellen, das die grundlegenden Formen und Verfahren dieses ersten hispanoamerikanischen Romans im vollen Wortsinne sichert. Doch eine kurze Anmerkung zu diesem Aspekt des literarischen Raumes im neuspanischen Roman sei an dieser Stelle erlaubt! In einer Reihe bereits angeführter Untersuchungen sind die Bezüge des Periquillo Sarniento zu Fénelons Télémaque herausgearbeitet worden. Die notwendige Erhellung der vielfältigen intertextuellen Beziehungen zwischen Fernández de Lizardis Roman und Raynals von der Zensur verbotenem, gleichwohl den neuspanischen Zeitgenossen aber bekanntem und in mehreren Exemplaren in mexikanischen Bibliotheken vorhandenem Monumentalwerk über die koloniale Expansion Europas kann im Rahmen dieser Arbeit nur erwähnt werden. Jedoch verdeutlicht diese Erwähnung, wie präsent französischsprachige Texte bereits an der Jahrhundertwende im kolonialspanisch-amerikanischen Raum waren.

Es kann keinerlei Zweifel daran geben: Möglichst zahlreiche und weitgespannte Lektüren und deren Vermittlung legitimieren den Schriftsteller neuen Typs, wie ihn Fernández de Lizardi am Ausgang der spanischen Kolonialherrschaft repräsentierte! Dabei entstand ein innerliterarischer Raum, der weit über die spanischsprachige Welt hinausreichte. Zugleich wurde schon in den Vorworten des Periquillo Sarniento verschiedentlich explizit auf die Tatsache aufmerksam gemacht, dass sich der Roman auch allgemeiner Nachschlagewerke oder Zitatenschätze bediente, wie die expliziten Verweise etwa auf die damals verbreiteten Publikationen von Moréri ${ }^{63}$ oder Muratori ${ }^{64}$ - um es hier bei diesen beiden Beispielen zu belassen - bereits paratextuell andeuten.

Seit der grundlegenden Arbeit von Jefferson Rea Spell ${ }^{65}$ sind die zahlreichen ,Quellen' Fernández de Lizardis immer wieder namhaft gemacht, dabei aber selten in ihrer intertextuellen Funktionalität untersucht worden. Jean Franco ${ }^{66}$

63 Fernández de Lizardi, José Joaquín: El Periquillo Sarniento, S. 2.

64 Ebda., S. 6.

65 Vgl. Spell, Jefferson Rea: The Life and Works of José Joaquín Fernández de Lizardi. Philadelphia: University of Pennsylvania 1931.

66 Vgl. Franco, Jean: La heterogeneidad peligrosa. 
machte darauf aufmerksam, dass bereits die kolonialspanischen Behörden bei ihrer Anklageerhebung gegen Fernández de Lizardi die vielfältigen Beziehungen zu Texten und Vorstellungen anderer Autoren hervorhoben und dem Herausgeber des Pensador Mexicano bescheinigten, im Wesentlichen die Ideen anderer zusammengestoppelt zu haben. Franco hat bezüglich dieser Problematik mit Recht darauf verwiesen, dass es der Leserschaft Fernández de Lizardis nicht so sehr auf originelle Ideen, als auf die Vermittlung der zum damaligen Zeitpunkt im Umlauf befindlichen ,modernen' Vorstellungen ankam.

Untersucht man den innerliterarischen Raum des Periquillo Sarniento in seiner Gesamtheit, so wird mithin deutlich, dass gleichsam unterhalb der explizit stärker an Literatur und Philosophie Spaniens ausgerichteten Ebene ein eher implizites Verweissystem erkennbar wird. Dieses lässt die nicht-spanischen Literaturen Europas und allen voran die französische Literatur und Philosophie in ihrer großen Bedeutung für diesen Roman (wie für Fernández de Lizardis Denken überhaupt) hervortreten. Der literarische Raum des Periquillo Sarniento weist damit bereits Züge jenes grundlegenden und in unserer Vorlesung bereits skizzierten geokulturellen Dominantenwechsels auf, wie er dann im hispanoamerikanischen Roman der Romantik wenige Jahre später in aller Schärfe hervortreten sollte. An die Stelle der vorbildgebenden spanischen Literatur wird eine vorherrschende Ausrichtung an England und insbesondere Frankreich treten; ein Wechsel, wie er sich in El Periquillo Sarniento 1816 unverkennbar andeutet. Scheint das architextuelle Grundmuster auch spanisch determiniert zu sein, so wird in dessen intertextueller Auffüllung selbst innerhalb der Novela picaresca das Vorrücken französischer Vorbilder doch greifbar und anschaulich.

Lässt sich El Periquillo Sarniento als eine Übersetzung des ursprünglich spanischen Gattungsmodells in neuspanische Kontexte verstehen, so liegen auch den intertextuellen Beziehungen, die den literarischen Raum dieses Romans prägen, in großer Häufigkeit Übersetzungsprozesse zugrunde. Fasste man die hispanoamerikanischen Literaturen wie die lateinamerikanischen Kulturen insgesamt paradigmatisch als ausgeprägte Übersetzungskulturen auf, ${ }^{67}$ dann ließe sich bereits dieser erste Roman eines Hispanoamerikaners als charakteristisches Produkt einer kulturellen Tradition verstehen, innerhalb derer Übersetzungsprozessen höchste Bedeutung zukommt. Hatte bereits die vorherrschend intralinguale Übersetzung der Kolonialzeit den sich auf amerikanischem Boden angesiedelten Kolonien ihr eigenes Gepräge gegeben, so sind es seit dem letzten Drittel

67 Vgl. hierzu u. a. Pérez Firmat, Gustavo: The Cuban Condition: Translation and Identity in Modern Cuban Literature. Cambridge: Cambridge University Press 1989; Hinweise hierzu auch in Altamirano, Carlos / Sarlo, Beatriz: Literatura y sociedad. Buenos Aires: Hachette 1983. 
des 18. Jahrhunderts verstärkt Übersetzungsprozesse zwischen verschiedenen Sprachen, die den kulturellen und literarischen Horizont der amerikanischen Autoren prägend gestalten.

Übersetzung erscheint damit als kulturelles Paradigma Lateinamerikas. Auch dies ist ein grundlegender Aspekt, der in diesem „texto fundador“ seinen literarischen Ausdruck erhält und in Hinblick auf die Ausbildung nationaler wie nationalliterarischer Räume im 19. Jahrhundert von größter Wichtigkeit ist. Der interkulturelle Raum ist daher in dem hier untersuchten Roman wie in Neuspanien insgesamt durch vielfältige Übersetzungsprozesse gekennzeichnet, welche auch für die amerikanischen Varianten des Spanischen nicht vernachlässigt werden dürfen. Dass derartige Übersetzungen nicht nur wie bereits erwähnt das Lateinische, sondern auch bestimmte kulturelle Ausdrucksformen der indigenen Völker betreffen, kann uns der in der bereits zitierten Anmerkung des fiktiven Herausgebers fast selbstverständliche und daher kaum bemerkte Translationsprozess zeigen. Er weist nämlich nach, wie ein im Schriftbild anders markiertes Element integriert werden kann: ,itacate, que es un envoltorio con cosas de comer y algunos realillos.“ 68

Dass dieser indigene Begriff gerade dem Bereich der Begräbnisrituale entnommen ist, mag für den eigenen Standpunkt des an abendländischen Werten und Modellen orientierten Moralisten und Aufklärers Fernández de Lizardi vielleicht symptomatisch sein. Doch erlaubt der Text des Periquillo Sarniento gleichsam jenseits der an abendländischen Kulturvorgaben und Normen orientierten Vorstellungen des novohispanischen Autors Verbindungen und Lesarten, welche die Vielfalt der Sprachen und Kulturen nicht zuletzt anhand ihrer wechselseitigen Übersetzungen und Dialoge anschaulich werden lassen. El Periquillo Sarniento selbst ist das ästhetisch geglückte Ergebnis des Versuchs, die einem breiteren Publikum wohlvertraute Form des spanischen Schelmenromans nach Neuspanien kulturell wie romantechnisch zu übersetzen. Die interkulturelle Übersetzung ist dabei ein zentrales Verfahren polylogischen Schreibens im europäisch-amerikanischen Spannungsfeld und verdeutlicht, wie sehr beide Seiten des Atlantiks und damit beide ,Welten' im Titel unserer Vorlesung - in einer intensiven, wenn auch asymmetrischen Austauschbeziehung stehen.

Doch versuchen wir nun, unser Augenmerk abschließend auf die unterschiedlichen Formen der Mobilität im Roman zu richten! Dem am Ausgang der spanischen Kolonialherrschaft in Neuspanien entstandenen Schelmenroman

68 Fernández de Lizardi, José Joaquín: El Periquillo Sarniento, S. 99: „ein Itacate, eine Art Säckchen mit allerlei Dingen zum Essen nebst einigen Münzen.“ 
José Joaquín Fernández de Lizardis liegen verschiedene Bewegungen und Bewegungsrichtungen zugrunde, die es sich zu analysieren lohnt.

Zunächst erzählt der Roman die grundsätzlich chronologisch angelegte Entwicklung seines Protagonisten von Periquillo zu Pedro Sarmiento, vom Handelnden zum Erzählenden oder - wie dies bereits für die intertextuellen Modelle des Lazarillo de Tormes, des Guzmán de Alfarache oder des Gil Blas de Santillane gesagt werden kann - vom Handelnden zum Schreibenden, vom „actor“ zum „auctor“. Damit liegt dem Roman eine individuelle Lebensgeschichte zu Grunde, die - wie wir sahen - von der Geburt bis zum Tode des Helden reicht und nicht in Form einer Autobiographie, wohl aber mit autobiographischem Gestus erzählt wird. Dass Fernández de Lizardi die Formen der modernen Autobiographie bekannt waren und zur Verfügung standen, wie sie Jean-Jacques Rousseau entwickelt hatte, ist ohne jeden Zweifel gegeben.

Setzen wir diese individuelle Lebensgeschichte in Beziehung zur kollektiven Geschichte und der im Kern zwischen 1771/1773 und 1813/1816 angesiedelten Romandiegese, so ergibt sich die gegenläufige Bewegung eines „chassé-croisé“. Denn der Entwicklung von der Geburt zum Tode des Protagonisten entspricht eine Entwicklung vom Tod der alten Gesellschaft bis zur schmerzens- und blutreichen Geburt neuer gesellschaftlicher Verhältnisse in Amerika. Die Entstehungszeit des Romans fällt in eine Epoche eskalierender sozialer und politischer Konflikte, wie sie besonders spektakulär in den Erhebungen der Bauern und der indianischen Landbevölkerung gegen die spanische Herrschaft sowie die kolonialspanische Verwaltung zum Ausdruck kamen.

Diese historisch nicht lange zurückliegenden Ereignisse konnten allerdings zum damaligen Zeitpunkt nur sehr verdeckt angedeutet und keinesfalls positiv gedeutet werden. Daher verweist der weise Pedro Sarmiento auch nur kurz, unmittelbar vor der Übergabe der ,Autorschaft“ an seinen Freund „Lizardi“, auf die politischen Ereignisse nach 1810: „Doch wenden wir unsere Feder ab von einem seiner Natur nach so grässlichen Gegenstande, und beschmutzen wir die Seiten meiner Geschichte nicht willentlich mit den Erinnerungen an eine mit amerikanischem Blut gefärbte Epoche.“69

$\mathrm{Zu}$ dieser gegenläufigen Bewegung individueller Geschichte („mi historia“) und einer von „amerikanischem Blut“ gefärbten Historie tritt aber eine Bewegungsökonomie hinzu, die sich aus der konstruktiven Anlage des Schelmenromans leicht ableiten lässt. Dabei entspricht den unsteten Bewegungen des

69 Ferenández de Lizardi, José Joaquín: El Periquillo Sarniento, S. 453: „pero apartemos la pluma de un asunto tan odioso por su naturaleza, y no queramos manchar las páginas de mi historia con los recuerdos de una época teñida con sangre americana.“ 
erzählten Ich die Ruhe, ja bisweilen Bewegungslosigkeit des erzählenden Ich. Der Dynamik Periquillos ist die Statik Don Pedros ebenso offenkundig wie gattungskonform entgegengesetzt. Dieser Kontrast verbürgt als gattungskonstitutives Merkmal die Dialektik von individueller und kollektiver Geschichte und, quer dazu verlaufend, von offener und geschlossener Form.

Neben den am Anfang unserer Untersuchung genannten Gründen mag auch dies ein Motiv dafür sein, dass in der erzählenden Prosa der Sattelzeit des hispanoamerikanischen Romans vor der Romantik gerade den gattungsspezifischen Elementen des Schelmenromans eine so wichtige Rolle zukommt. Herausragende Beispiele hierfür sind sicherlich ebenso El Lazarillo de ciegos caminantes von Alonso Carrió de la Vandera wie die autobiographischen Schriften Fray Servando Teresa de Miers, die ohne die Novela picaresca schlechterdings nicht vorstellbar wären. Doch mit Fray Servando, einer Lieblingsfigur der beiden kubanischen Schriftsteller José Lezama Lima und Reinaldo Arenas, werden wir uns gleich im anschließenden Kapitel - und zum Teil auch in der Vorlesung zum 18. Jahrhundert - beschäftigen, so dass die Texte des neuspanischen Dominikanermönches noch nicht an dieser Stelle eingebaut werden sollen. ${ }^{70}$

Auf der gattungsspezifischen beziehungsweise architextuellen Ebene lässt sich die angesprochene Bewegungsökonomie reinterpretieren als Dialektik zwischen der Offenheit narrativer Formen und der Geschlossenheit diskursiver Passagen des Periquillo Sarniento. Die im Rahmen des Schelmenromans im Guzmán de Alfarache erstmals breit erprobte Dialektik von Erzählung und Belehrung, Lebensgeschichte und Kommentar, von - wie es in Mateo Alemáns Vorwort schon hieß - „conseja“ und „consejo“ findet im Periquillo Sarmiento literarisch ihren kreativen Niederschlag. Der Wechsel zwischen Narration und kommentierender Digression ist dabei keineswegs so angelegt, dass die kommentierenden und moralisierenden Einschübe allein der Erzählerfigur Pedro Sarmiento aufgebürdet würden. Sie sind vielmehr auf verschiedene Instanzen (etwa den intradiegetischen Herausgeber) und literarische Figuren übertragen, wobei eine moralisch verankerte, aber zeitgenössisch brisante Gesellschaftskritik sehr wohl ,unmoralischen' Figuren in den Mund gelegt werden kann, um deren Aussagen dann durch zusätzliche Erzähler- oder Herausgeberkommentare scheinbar relativieren oder

70 Vgl. zu dieser faszinierenden Figur bereits Ette, Ottmar: Der Blick auf das Andere. Eine kontrastive Lektüre der Reisen Alexander von Humboldts und Fray Servando Teresa de Miers. In: Schlieben-Lange, Brigitte et al. (Hg.): Europäische Sprachwissenschaft um 1800. Bd. 2: Methodologische und historiographische Beiträge zum Umkreis der „idéologie“. Münster: Nodus Publikationen 1991, S. 137-171. 
gar konterkarieren zu können. Dies ist unter den Bedingungen einer sehr aktiven neuspanischen Zensur ein probates Verfahren.

Zugleich vermeiden derartige literarische Verfahren ein monotones Pendeln zwischen erzählter Zeit und Erzählzeit, zwischen fiktionalen und nicht-fiktionalen Formen, zwischen ,erzählen' und ,belehren'. Ich habe bereits auf die Tatsache verwiesen, dass die umfangreichen diskursiven (,moralisierenden') Passagen innerhalb der Rezeptionsgeschichte bis zum heutigen Zeitpunkt oftmals als störende didaktische Einschübe verstanden (oder besser missverstanden) wurden. Doch beruht die Ökonomie des Schelmenromans in der Nachfolge des Guzmán de Alfarache darauf, dass die erzählenden Passagen auch ,belehrenden' Charakter besitzen und die ,Belehrungen' zugleich auch wieder die Handlung vorantreiben, so dass ein Wechselspiel zwischen diskursiven und narrativen Romanteilen entsteht.

Dass dies Fernández de Lizardi nicht immer gelang, darf nicht davon ablenken, dass El Periquillo Sarniento nicht als diskursiv überladener Lebensbericht eines reuigen Pícaro gedacht werden darf, aus dem die kommentierenden Teile ohne Verlust sorgsam herausgetrennt werden könnten. Entsprechende Ausgaben sind grob verfälschend. Das Buch zerfällt nicht in zwei Bücher, bei denen man auf eines verzichten kann, sondern wurde als prekäre Einheit von Narration und Diskurs oder (im Sinne Genettes) von Fiktion und Diktion konzipiert. Wir dürfen diese Einheit nicht anachronistisch zerstören, sondern müssen sie in ständiger Bewegung zwischen Offenheit und Geschlossenheit, Dynamik und Statik halten und verstehen.

Dabei sind Fiktion und Diktion nicht in voneinander getrennte Bereiche fixiert, sondern treten in ständige Spiegelungen und Reibungen ein. So bildet sich der erste hispanoamerikanische Roman im Kontext eines Wechselspiels diktionaler und fiktionaler Schreibformen als Verkörperung einer friktionalen Schreibweise heraus, wie sie für die lateinamerikanischen Literaturen bis heute prägend geblieben ist. ${ }^{71}$ Damit erweist sich der erste von einem Hispanoamerikaner in Spanisch-Amerika verfasste Roman als Beispiel friktionaler Literatur. Diesen Roman gemäß eines normativen Gattungsverständnisses, das vorwiegend durch den europäischen Roman des 19. Jahrhunderts geprägt wurde, auf seine fiktionalen Bestanteile zu reduzieren hieße, ihn als ästhetisches Artefakt mit seiner ihm eigenen Komplexität zu zerstören.

71 Zur Definition friktionaler Literatur und Schreibweisen im Kontext eines modernistischen Schreibens im Spannungsfeld zwischen Europa und Amerika vgl. Ette, Ottmar: „Así habló Próspero“. Nietzsche, Rodó y la modernidad filosófica de „Ariel“. In: Cuadernos Hispanoamericanos (Madrid) 528 (junio 1994), S. 48-62. 
Dass Fernández de Lizardi seinen Roman als Einheit betrachtete, mag schon aus der Tatsache hervorgehen, dass an verschiedenen Stellen dieses Textes auf eine wechselseitig sich verstärkende Wirkung seiner heterogenen Ingredienzien aufmerksam gemacht wird. So lesen wir im vierzehnten Kapitel des ersten Teils:

Das gute Beispiel bewegt mehr als alle Ratschläge, Andeutungen, Predigten und Bücher. Das alles ist gut, aber letztlich sind es Worte, die fast immer der Wind verweht. Über die Augen prägt sich die Lehre fester ein als über die Ohren. ${ }^{72}$

Und wenige Zeilen vor dem Ende des letzten Romankapitels, in welchem erneut in Form eines Dialogs zwischen dem fiktiven Herausgeber und der Witwe Pedro Sarmientos, der Inhaberin der Autorenrechte ihres Mannes also, auf die Nützlichkeit des Buches für das Lesepublikum hingewiesen wird, treffen wir erneut auf die Spezifik von Auge und Ohr. „Lizardi“ begründet seine Hochschätzung des Lebensberichts seines Freundes mit den folgenden Worten:

Gewiss, die moralischen Bücher belehren, aber nur durch die Ohren; und deshalb sind ihre Lektionen schnell vergessen. Werke wie das vorliegende aber unterrichten durch die Ohren wie durch die Augen. [...] Wenn wir von diesen Tatsachen lesen, so erscheint es uns, als ob wir sie selbst sähen, und so behalten wir sie im Gedächtnis [...]. ${ }^{73}$

Auge und Ohr haben seit der abendländischen Antike recht unterschiedliche Aufgabenfelder in Zusammenhang mit literarischen oder historiographischen Werken. ${ }^{74}$ Denn die Koppelung von Informationsaufnahme, Sinnesleistung, Gedächtnis und jeweiligem historisch-kulturellen Kontext ist von hoher Komplexität geprägt und variiert von Epoche zu Epoche. Nicht immer war es so wie in unserer aktuellen Gesellschaft und Zivilisation, in welcher die Informationsaufnahme über das Auge - im Zeichen der Fenster von Windows und der allgegenwärtigen Bildschirme - zu über achtzig Prozent über das Auge erfolgt. Aber für Fernández de Lizardi sind längst schon die Zeiten historisch, in welchen die katholische Kirche dem Auge und der „concupiscentia oculorum“ misstraute und ganz auf das Ohr als das Sinnesorgan des Christenmenschen setzte, der dem gesprochenen Worte $\mathrm{zu}$ gehorchen hatte. Lizardi vertraut bereits stärker dem

72 Fernández de Lizardi, José Joaquín: El Periquillo Sarniento, S. 113.

73 Ebda., S. $463 \mathrm{f}$.

74 Vgl. zu diesem Themenfeld Ette, Ottmar: Diderot et Raynal: l'oeil, l'oreille et le lieu de l'écriture dans l',Histoire des deux Indes“. In: Lüsebrink, Hans-Jürgen / Strugnell, Anthony (Hg.): L', ,Histoire des deux Indes“: réécriture et polygraphie. Oxford: Voltaire Foundation 1996, S. 385-407. 
Auge, präferiert zu Beginn des 19. Jahrhunderts aber offenkundig eine Kombination von Auge und Ohr.

Denn in seinem Periquillo Sarniento ist es das Ziel eines auf Wirkung und Erinnerung berechneten Schreibens, Hör- und Gesichtssinn, Augen und Ohren der Leserschaft gleichermaßen anzusprechen. Aufgabe eines solchen Buches wie seines Schelmenromans ist es daher, mehr zu sein als Bücher, das eigene Medium der bloßen Worte damit zu überschreiten. Nicht nur die „consejos“, sondern - so dürfen wir ergänzen - auch deren Zusammenspiel mit den „consejas“ steht im Zentrum der Aufgabe und Arbeit des Schreibenden. Aber was ist mit dieser Arbeit gemeint?

Bei Fernández de Lizardi treffen wir wohl erstmals auf eine Konzeption schriftstellerischen Tuns, die sich auf Arbeit gründet - eine Konzeption, auf die wir etwa bei einem Gustave Flaubert und dessen Arbeitsethik wieder stoßen werden. Diese schriftstellerische Arbeit, so erfahren wir in El Periquillo Sarniento, besteht in ganz wesentlicher Weise darin, nicht nur ein bestimmtes Lesepublikum an die Literatur heran, sondern diesem Publikum auch erbauliche Exempla vor Augen zu führen.

Das Ohr, bekanntermaßen das Organ des wahren Christen und rechten Glaubens, vertraut allein dem Medium Luft, dem Wind, der die Worte der Predigt mit sich trägt. Das Auge dagegen wird durch Lebensbilder angesprochen, die im Gedächtnis festgehalten werden können oder sich, wie es in dieser Passage heißt, dem Gedächtnis einprägen (,imprime“). Nicht anders wird Próspero in José Enrique Rodós Ariel am Ende des 19. Jahrhunderts von seinen Schülern fordern, sich das Bild des von ihm beschworenen Luftgeists einzuprägen: „Ich will, dass das leichte und anmutige Bild dieser Bronze sich von nun an dem sichersten Ort im Inneren Eures Geistes einprägt. “75

Die Bedeutung, die im Periquillo Sarniento dem Auge für die Kraft der Memorisierung beigemessen wird, steht dabei zweifellos mit jener Dominanz des Auges in Zusammenhang, die sich seit dem Übergang vom 18. zum 19. Jahrhundert im Bereich der epistemologischen Grundlagen menschlicher Erfahrung nachweisen lässt. ${ }^{76}$ Nicht Auge oder Ohr, nicht „,consejas“ oder „consejos“, nicht Fiktion oder

75 Rodó, José Enrique: Ariel. Übersetzt, herausgegeben und erläutert von Ottmar Ette. Mainz: Dieterich'sche Verlagsbuchhandlung 1994, S. 186; sowie (ders.): Ariel. Edición de Belén Castro Morales. Madrid: Anaya \& Mario Muchnik 1995, S. 96 f: „Yo quiero que la imagen leve y graciosa de este bronce se imprima desde ahora en la más segura intimidad de vuestro espíritu.“

76 Vgl. hierzu Ette, Ottmar: La mise en scène de la table de travail: poétologie et épistémologie immanentes chez Guillaume-Thomas Raynal et Alexander von Humboldt. In: Wagner, Peter (Hg.): Icons - Texts - Iconotexts. Essays on Ekphrasis and Intermediality. Berlin - New York: Walter de Gruyter 1996, S. 175-209. 
Diktion, sondern jeweils beides zusammen soll auf den zu bildenden Leser einwirken. José Joaquín Fernández de Lizardi ist damit absolut auf Augenhöhe mit jenen grundlegenden Veränderungen menschlicher Wahrnehmung und menschlichen Verstehens, die sich zu seiner Zeit im Bereich abendländischer Zivilisation vollzogen haben. Wir werden im weiteren Verlauf unserer Vorlesung noch verschiedentlich auf diesen fundamentalen Wandel in der Gewichtung der Sinneswahrnehmungen stoßen.

Dies führt uns zur Problematik des in Neuspanien erst noch zu bildenden neuen Lesepublikums zurück. Wir können uns dieser Fragestellung nun aus einer neuen Perspektive nähern, indem wir die Bewegungen des Pícaro auf Ebene der erzählten Zeit - also zwischen seiner Geburt um 1771 und seinem Tod im Jahre 1813 - als Bewegungen eines Verstehens nachvollziehen und analysieren. Dabei ist es möglich, die Deplatzierungen des Protagonisten in El Periquillo Sarniento in Beziehung zu setzen zu verschiedenen Bewegungs- und Verstehens-Modellen, von denen sich mindestens fünf verschiedene Grundfiguren unterscheiden lassen: Erstens eine kreisförmige Reisebewegung, die den Reisenden wieder an seinen Ausgangsort zurückführt; zweitens ein Pendeln des Reisenden zwischen zwei oder mehreren Orten; drittens eine lineare Bewegung von einem Ausgangszu einem Zielpunkt; viertens eine sternförmige Bewegung, die den Reisenden immer wieder zu seinem Ausgangspunkt zurück und von diesem ausgehend wieder $\mathrm{zu}$ neuen Bewegungen führt; und schließlich fünftens die Grundfigur eines Springens, die weder über einen konkreten Ausgangs- noch über einen konkreten Zielpunkt verfügt und sich der Diskontinuität von Reisebewegungen sowie dem Spiel des Zufalls öffnet. ${ }^{77}$ Diese spatialen Grundbewegungen des Verstehens können wir als die hermeneutischen Bewegungsfiguren literarischen Schreibens bezeichnen, auf die ich in dieser Vorlesung ebenfalls noch mehrfach zurückkommen werde.

Versuchen wir, diese fünf Grundfiguren von Verstehens-Bewegungen im Raum auf Fernández de Lizardis Roman zu beziehen, so bemerken wir bald, dass im Periquillo Sarniento verschiedene Bewegungsfiguren miteinander kombiniert wurden: Zwar ist der ,Reiseweg‘ des neuspanischen Pícaro - vergleichbar mit seinen spanischen Vorgängern - in grundlegender Weise vom Zufall und den zufälligen Bekanntschaften im Verlaufe dieses Weges bestimmt, doch ist für die gesamte Struktur des Romans eine eher sternförmige Anlage festzustellen, die sehr wohl von den intertextuellen spanischen Vorbildern abweicht.

77 Vgl. hierzu in der Reihe „Aula“ die erste Vorlesung von Ette, Ottmar: ReiseSchreiben. Potsdamer Vorlesungen zur Reiseliteratur. Berlin - Boston: Walter de Gruyter 2020, S. 196-235. 
Denn wenn wir in den gesamten Reiseverlauf eingebettete kreisförmige Reisestrukturen wie etwa die Reise auf die Philippinen mit Hinweg und Rückweg über Acapulco außer Betracht lassen, können wir die Bewegungen des Pícaro zwar in gewisser Weise einem itinerarischen Schema zuordnen, das von Digressionen und Exkursionen unterbrochen wird. Doch dominiert über den gesamten Romanverlauf zweifellos eine Kombination aus vierter und fünfter Grundfigur, so dass wir von einer mehr oder minder vom Zufall bestimmten, aber stets am Zentrum der Hauptstadt Mexiko sternförmig orientierten zentripetalen Verstehens-Bewegung sprechen dürfen. Damit zeigt sich nicht nur die Aufhebung einer offenen in einer geschlossenen Form, sondern zugleich auch die Ausrichtung einer weiten Landfläche an einem zentralen Ort: der Hauptstadt des Vizekönigreichs Neuspanien. Es sind Bewegungsfiguren, die - wenn wir sie auf einen erst noch zu schaffenden nationalen Raum beziehen - unverkennbar einen zentrierten und zentralisierten Staat skizzieren, welcher in all seinen Teilen an der Hauptstadt Mexiko-Stadt ausgerichtet ist.

Die Abweichung Periquillo Sarnientos vom gattungskonformen Bewegungsschema des spanischen Schelmenromans ist insoweit signifikant, als sich hier folglich - allen Zufällen zum Trotz -eine zentralisierte Bewegung durchzupausen vermag, die sehr wohl mit den politischen Zuständen im Vizekönigreich, aber auch mit der Zentralisierung des künftigen mexikanischen Nationalstaats in Beziehung gesetzt werden darf. Eine solche Feststellung ist unabhängig von all jenen Auseinandersetzungen, die sich im gerade unabhängig gewordenen Staatsgebilde die Anhänger föderaler und zentralstaatlicher Strukturen lieferten. Es ist ein politisch erbittert geführter Kampf zwischen zwei miteinander verfeindeten Positionen, die sich beispielsweise im Werk des bereits erwähnten Dominikanermönchs Fray Servando Teresa de Mier deutlich abzeichnen und die wir im anschließenden Kapitel näher besprechen wollen. Doch auch im weiteren Fortgang unserer Vorlesung wird dieser Antagonismus eine Rolle spielen.

Zugleich erlaubt es die Sternfigur, auch auf Ebene der erzählten Zeit selbst jenen für die Ökonomie des Schelmenromans grundlegenden Wechsel zwischen Bewegung und Ruhe einzuführen, der die Modellierung bestimmter Umbrüche erlaubt. Begreifen wir die Bewegungen des Pícaro im Raum als hermeneutische Verstehens-Prozesse, die vom Lesepublikum nachvollzogen werden sollen, dann überrascht es nicht, dass die Modellierung bestimmter Orte, an denen sich wichtige Veränderungen ergeben, topisch akzentuiert werden muss.

Diese Orte des Wandels aber werden nicht wie an anderen Stellen nur durch diskursive Passagen, sondern vor allem durch verortete Gedichte bezeichnet. Es handelt sich dabei um lyrische Ausdrucksformen individueller Bewusstwerdung, die bestimmten Orten innerhalb der hermeneutischen Bewegungsabläufe zugeordnet werden können. Diese Gedichte und lyrischen Formen akzentuieren ein 
individuelles Innewerden, einen Augenblick verdichteter Selbstreflexion und damit ein Selbstverständnis des Protagonisten, welches dieser mit seinem Lesepublikum teilt. Die in den Romanablauf integrierten Gedichte punktieren und rhythmisieren die hermeneutischen Bewegungen des romaninternen Protagonisten wie des romanexternen Lesepublikums und übernehmen auf diese Weise eine wichtige Funktion in den Verstehens-Prozessen des Romans. Das durch den Gattungswechsel notwendige Innehalten dieses Lesers an bestimmten Orten des vom Pícaro durchlaufenen Reiseweges führt dabei zu einer Spatialisierung der Verstehens-Prozesse und damit zu einer effektiven, augenfälligen Übertragung der hermeneutischen Bewegung auf die Rezipienten. Wichtige Wendepunkte des Lebensweges werden auf diese Weise semantisch aufgeladen und der Leserschaft plastisch vor Augen geführt.

Die von einer aktiven Leserschaft nachzuvollziehende hermeneutische Bewegung ist an den nationalen, an der Hauptstadt Mexiko ausgerichteten Raum gekoppelt. Wie in der Forschung bereits nachgewisen wurde, ${ }^{78}$ ist der Begriff „sociedad“ in Fernández de Lizardis Gesamtwerk bereits am modernen Gesellschaftsbegriff Rousseau'scher Provenienz orientiert, wobei die in Szene gesetzte Vorstellung einer patriarchalisch am Vater ausgerichteten Familienstruktur in nuce die grundlegende Sozialstruktur abbildet. Daher lässt sich ein erst noch zu schaffendes nationales Lesepublikum, das die Arbeit des Schriftstellers honoriert und den Einfluss des „escritor público“ auf die Formierung der neuen Gesellschaft stärkt, als die grundlegende Vermittlungsebene zwischen einem modern konzipierten Gesellschaftsbegriff und einer neu definierten Rolle des Schriftstellers innerhalb dieser Gesellschaft begreifen. Es gibt mithin gute Gründe dafür, El Periquillo Sarniento nicht nur als den chronologisch ersten hispanoamerikanischen Roman zu verstehen: José Joaquín Fernández de Lizardis Roman eröffnet auf eine fundamentale Weise ein neues Jahrhundert des Schreibens innerhalb jenes Raumes, den wir heute als Lateinamerika bezeichnen.

El Periquillo Sarniento signalisiert die sich langsam herausbildende Konstituierung eines Lesepublikums für literarische Artefakte in jenen politischen und gesellschaftlichen Strukturen, die sich im Übergang von der kolonialen zur postkolonialen „ciudad letrada“ befinden. Innerhalb dieser Gemeinschaft der Lesenden kommt dem Schriftsteller neuen Typs eine zentrale und als patriarchalisch zu bezeichnende intellektuelle Leitfunktion $\mathrm{zu}$ - zumindest eine leitende Funktion, welche von diesem Schriftsteller und Schreibenden für sich eingefordert wird.

78 Janik, Dieter: „El Periquillo Sarniento“ de J.J. Fernández de Lizardi: una normativa vacilante (sociedad - naturaleza y religión - razón). In: Ibero-Amerikanisches Archiv (Berlin) XIII, 1 (1987), S. 49-60. 
Es ist daher nicht nur die Kommunikationssituation zwischen einem Vater und seinen Kindern, sondern mehr noch jene zwischen einem von Mäzenen unabhängigen Schriftsteller und seinem sich formierenden Lesepublikum, das die Grundstrukturen einer künftigen neuen Gemeinschaft der Literatur vorwegnimmt. Dass es sich dabei um jene Gemeinschaft handelt, die Goethe wenige Jahre später als „Weltliteratur“ bezeichnete, werden wir im weiteren Verlauf unserer Vorlesung sehen.

Aus all diesen Zusammenhängen erklärt sich das ganze Gewicht, das dem paratextuellen in seiner Verbindung zum protonationalen oder nationalen Raum zukommt. Ist die Beziehung zwischen Literatur und Nation im hispanoamerikanischen Roman der Romantik über die (zumeist missglückende) Liebesgeschichte in Form einer nationalen Allegorese vermittelt, geschieht dies 1816 im Periquillo Sarniento über die erst noch zu definierende Beziehung zwischen einem sich am Literaturmarkt orientierenden Schriftsteller neuen Typs und einem nationalen Lesepublikum. Dieses galt es trotz seiner sozialen, rassischen und kulturellen Heterogenität als potentielle Käuferschicht anzusprechen und $\mathrm{zu}$ gewinnen. Es gibt wohl kaum einen Roman des entstehenden Lateinamerika, der diesen Prozess klarer und reflektierter darstellen könnte, als jenen des wohl ersten von seiner eigenen Arbeit lebenden Schriftstellers der Neuen Welt: des neuspanischen Mexikaners José Joaquín Fernández de Lizardi.

Das Ziel dieses heute vielleicht noch immer etwas unterschätzten Autors war es, einer in Amerika geschriebenen Literatur, welcher der Zugang zum Lesepublikum in Spanien noch ein knappes Jahrhundert lang - bis zu den Erfolgen der „Modernistas“ - verwehrt bleiben sollte, ein eigenes Lesepublikum zu schaffen. El Periquillo Sarniento bezeichnet diesen für die weitere Entwicklung der lateinamerikanischen Literaturen entscheidenden Augenblick und erklärt ihn zum Ausgangspunkt seiner literarischen Kreation: Eben dies macht den Roman so einzigartig. Lassen Sie mich es durchaus etwas pathetisch sagen: Die Konstruktion des Nationalen als prä- und protonationaler Kommunikationsraum - und nicht so sehr die Kontingenz der Jahreszahlen - macht den ersten Roman des „Pensador Mexicano“ zu einem wahrhaften und wirkungsvollen Gründungstext der hispanoamerikanischen und perspektivisch der lateinamerikanischen Literaturen! 